\title{
Assessment of radiation forcing data sets for large-scale sea ice models in the Southern Ocean
}

\author{
Martin Vancoppenolle ${ }^{\mathrm{a}, \mathrm{b}, *}$, Ralph Timmermann ${ }^{\mathrm{c}}$, Stephen F. Ackley ${ }^{\mathrm{d}}$, Thierry Fichefet ${ }^{\mathrm{a}}$, Hugues Goosse ${ }^{\mathrm{a}}$, \\ Petra Heil ${ }^{\mathrm{e}}$, Katherine C. Leonard ${ }^{\mathrm{f}, \mathrm{g}}$, Jan Lieser ${ }^{\mathrm{e}}$, Marcel Nicolaus ${ }^{\mathrm{h}}$, Tim Papakyriakou ${ }^{\mathrm{i}}$, Jean-Louis Tison ${ }^{\mathrm{j}}$ \\ ${ }^{a}$ Georges Lemaître Centre for Earth and Climate Research, Earth and Life Institute, Université catholique de Louvain, Louvain-la-Neuve, Belgium \\ ${ }^{\mathrm{b}}$ Department of Atmospheric Sciences, University of Washington, Seattle, WA, United States

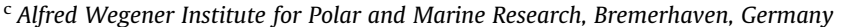 \\ ${ }^{\mathrm{d}}$ Department of Earth and Environmental Science, University of Texas at San Antonio, San Antonio, TX, United States \\ e ACE CRC \& Australian Antarctic Division, University of Tasmania, Hobart, Australia \\ ${ }^{\mathrm{f}}$ Lamont-Doherty Earth Observatory of Columbia University, Palisades, NY, United States \\ ${ }^{g}$ WSL Institute for Snow and Avalanche Research SLF, Davos, Switzerland \\ ${ }^{\mathrm{h}}$ Norwegian Polar Institute, Tromsø, Norway \\ i Centre for Earth Observation Science, University of Manitoba, Winnipeg, MB, Canada \\ ${ }^{\mathrm{j}}$ Laboratoire de Glaciologie, Université Libre de Bruxelles, Bruxelles, Belgium
}

\section{A R T I C L E I N F O}

\section{Article history:}

Received 20 October 2010

Accepted 20 October 2010

Available online 18 November 2010

Keywords:

Antarctic

Sea ice

Forcing

Radiation

Model

\begin{abstract}
A B S T R A C T
Little is known about errors in the atmospheric forcings of large-scale sea ice-ocean models around Antarctica. These forcings involve atmospheric reanalyses, typically those from the National Center for Environmental Prediction and National Center from Atmospheric Research (NCEP-NCAR), climatologies, and empirical parameterizations of atmosphere-ice heat and radiation fluxes.

In the present paper, we evaluate the atmospheric forcing fields of sea ice models in the Southern Ocean using meteorological and radiation observations from two drifting station experiments over Antarctic sea ice. These are Sea Ice Mass Balance in the Antarctic (SIMBA, Bellingshausen Sea, October 2007) and ISPOL (Ice Station POLarstern, Weddell Sea, December 2004). For the comparison, it is assumed that those point measurements are representative of the whole model grid cell they were collected in.

Analysis suggests that the NCEP-NCAR reanalyses have relatively low biases for variables that are assimilated by the system (temperature, winds and humidity) and are less accurate for those which are not (cloud fraction and radiation fluxes). The main deficiencies are significant day-to-day errors in air temperature (root-mean-square error $1.4-3.8^{\circ} \mathrm{C}$ ) and a $0.2-0.6 \mathrm{~g} / \mathrm{kg}$ mean overestimation in NCEP-NCAR specific humidity. In addition, associated with an underestimation of cloud fraction, NCEP-NCAR shortwave radiation features a large positive bias $\left(43-109 \mathrm{~W} / \mathrm{m}^{2}\right.$ ), partly compensated by a $20-45$ $\mathrm{W} / \mathrm{m}^{2}$ negative bias in longwave radiation. Those biases can be drastically reduced by using empirical formulae of radiation fluxes and climatologies of relative humidity and cloud cover. However, this procedure leads to a loss of day-to-day and interannual variability in the radiation fields. We provide technical recommendations on how the radiation forcing should be handled to reduce sea ice model forcing errors. The various errors in forcing fields found here should not hide the great value of atmospheric reanalyses for the simulation of the ice-ocean system.
\end{abstract}

(c) 2010 Elsevier Ltd. All rights reserved.

\section{Introduction}

The Southern Ocean is a key component of the climate system. The large uptake of heat and $\mathrm{CO}_{2}$ in the Southern Ocean significantly moderates global warming in future climate projections (e.g., Stouffer et al., 2006; Bitz et al., 2006; LeQuéré et al., 2007). An

\footnotetext{
* Corresponding author at: Georges Lemaître Centre for Earth and Climate Research, Earth and Life Institute, Université catholique de Louvain, Louvain-laNeuve, Belgium. Tel.: +32 10473064; fax: +32 10474722

E-mail address: vancop@astr.ucl.ac.be (M. Vancoppenolle).
}

important agent in the Southern Ocean is its sea ice cover (Goosse and Fichefet, 1999; Worby et al., 2008; Cavalieri and Parkinson, 2008).

Simulating the large-scale evolution of Antarctic sea ice has proved more difficult than for the Arctic. Hindcast simulations of the Antarctic sea ice pack forced by atmospheric and radiation data forcing (hereafter 'hindcasts') show reasonable agreement with observations in terms of large-scale distribution of ice thickness and concentration, but are not as accurate as those made for the Arctic (see, e.g., Vancoppenolle et al., 2009). This is illustrated by the statistics of a global sea ice 1979-2006 reconstruction 
Table 1

Model-data comparison statistics for the model NEMO-LIM3 (Vancoppenolle et al. 2009) for a global sea ice hindcast over 1979-2006 forced by a combination of NCEP atmospheric reanalyses (Kalnay et al., 1996) and climatologies at $2{ }^{\circ}$ resolution. Bias is defined as the average model-observation difference. Observed ice area is taken from passive microwave data (Comiso et al., 2008). Arctic ice thickness estimates come from submarine ice draft data set (Rothrock et al., 2008). Antarctic ice thickness data come from the ASPeCt data set (Worby et al., 2008). For more details on procedures, see Vancoppenolle et al. (2009).

\begin{tabular}{lcc}
\hline Diagnostic & Arctic & Antarctic \\
\hline Model-obs. relative bias on summer ice area (\%) & -21 & -71 \\
Model-obs. relative bias on winter ice area (\%) & -0.9 & 14 \\
Model—obs. relative bias on ice thickness (\%) & -17 & -44 \\
Correlation between model and obs. ice area variability & 0.74 & 0.65 \\
\hline
\end{tabular}

performed using their state-of-the-art global ice-ocean model (Table 1), which shows the following deficiencies. The main sea ice model errors in the Southern Ocean include an overestimation (underestimation) of winter (summer) sea ice extent, as well as an underestimation of mean ice thickness. This in turn deteriorates the simulated interannual variations. Some of these features were found in other Antarctic sea ice simulations (Fichefet et al., 2003; Timmermann et al., 2005; Stössel et al., 2007; Zhang, 2007; Mathiot, 2009; Timmermann et al., 2009). Another dilemma is that sea ice simulations performed with coupled climate models used in the last IPCC climate assessment show the same tendency of lower performance for the Antarctic than for the Arctic (Arzel et al., 2006). Averaged over all IPCC model simulations, the current sea ice is reasonably well reproduced. However, this averaging procedure hides large errors from individual models (Holland and Raphael, 2006; Lefebvre and Goosse, 2008).

Errors in Antarctic sea ice hindcasts have been attributed to grid resolution, missing physical processes in the models, and quality of available forcing data (see, e.g., Fichefet et al., 2003; Timmermann et al., 2005, 2009; Vancoppenolle et al., 2009). First, increasing horizontal model resolution improves simulation of the ice edge on some locations, but does not explain all simulation errors (Mathiot, 2009). Second, the effects of velocity divergence, formation of frazil/pancake ice and of snow cover (flooding, superimposed and snow ice formation) are more prevalent in the Antarctic than in the Arctic (e.g., Heil and Allison, 1999; Nicolaus et al., 2006; Heil et al., 2008; Lewis et al., 2011), and because these processes are not completely understood, they may not be adequately represented in current models. Finally, there are uncertainties associated with the forcing that are an important issue: at this stage, they complicate model physics improvements. As the Southern Ocean is poorly data-covered, the atmospheric reanalyses climatologies may carry significant errors (e.g., Bromwich and Fogt, 2004). However, over Antarctic sea ice, little is known on the skill of reanalysis products.

The NCEP-NCAR (Kalnay et al., 1996; Kistler et al., 2001) reanalyzed data of the atmospheric state over the last 50 years everywhere on Earth on a daily basis. Those extremely valuable data combine information from both weather prediction models and observations and are available on $\sim 2^{\circ}$ grids. Reanalyzed nearsurface temperature and pressure fields have been evaluated at high Southern latitudes using weather station data by Bromwich and Fogt (2004) and Bromwich et al. (2007). They mention poorer behavior in the Antarctic compared to the Arctic due to large data gaps, especially before 1978 . Reasonable skill was found after that year because of the introduction of satellite data in the system. In addition, a strong coastal cold bias, from 0 to $-15^{\circ} \mathrm{C}$, was found around Antarctica. However, Bromwich and Fogt (2004) mention that the latter is not extremely robust and rather indicates that the sharp change in altitude is not resolved by reanalysis systems. To our knowledge, the unique study evaluating reanalysis over Antarctic sea ice is the one by Vihma et al. (2002). Using temperature and wind data from floating buoys over a year in 1996, they found a cold bias of $-3.2{ }^{\circ} \mathrm{C}$ in NCEP and a warm bias of $3.5{ }^{\circ} \mathrm{C}$ in ECMWF reanalyses, inducing significant differences in turbulent fluxes of sensible and latent heat. Radiation fields in reanalysis systems were not assessed in that study. In the Arctic, a recent study by Walsh et al. (2009) suggests that reanalysis system contain large biases because of their inaccurate representation of clouds.

Errors in atmospheric reanalyses impact sea ice models through computation of the surface energy budget. Some information on observations of the latter over Antarctic sea ice can be found in Vihma et al. (2002, 2009) and Andreas et al. (2004). They indicate that the annual surface energy budget is dominated by the net longwave radiative loss, which is compensated about equally by incoming shortwave radiation and sensible heat. In summer, significant differences were found, in particular, an upwards sensible heat flux (Vihma et al., 2009). Over Antarctic sea ice long time series of meteorological products do not exist, so little is known about the skill of reanalysis products.

In this paper, we use field data from two Antarctic sea ice drifting stations, Sea Ice Mass Balance in the Antarctic [SIMBA], (Lewis et al., 2011) and Ice Station POLarstern [ISPOL] (Hellmer et al., 2008), to characterize the surface radiation budget over Antarctic sea ice in spring and early summer. In addition, we evaluate the errors in radiation fluxes in reanalyses and in the forcing formulations used in large-scale hindcast sea ice simulations. We assume that point measurements are representative of the whole model grid cell. This is likely a reasonable approximation for daily averages of most variables. However, the presence of polynyas or the proximity of the ice edge could influence the comparison.

\section{Material and methods}

\subsection{Drifting stations}

Two sets of in situ meteorological and radiation data from two sea ice drifting stations have been used here: SIMBA and ISPOL (see Fig. 1). Prior to analysis, the data discussed here were quality controlled and averaged on common hourly and daily bases.

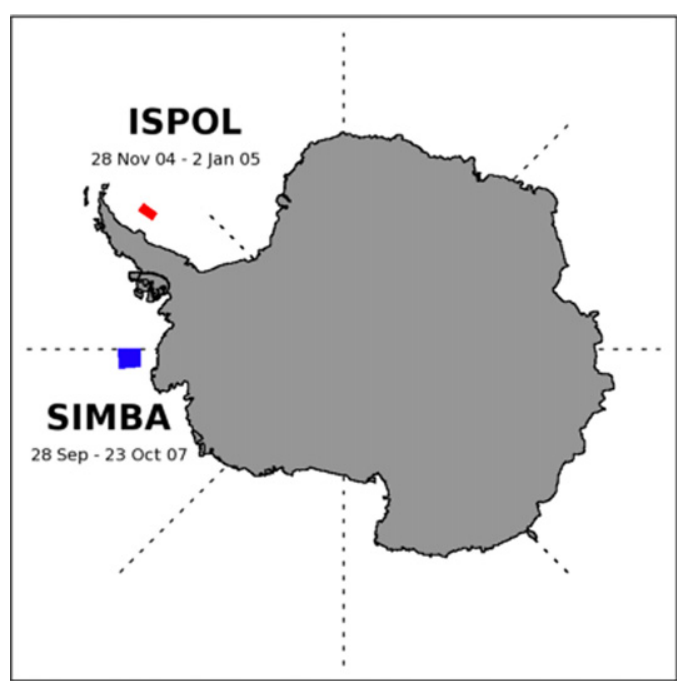

Fig. 1. Map of Antarctica with locations of SIMBA and ISPOL drifting stations. 
SIMBA took place in the Bellingshausen Sea in austral spring 2007. Between September 25-27 (days 268-270), ice stations were made on the way from the open ocean through the periphery of the sea ice due south into heavy pack. Then, the R/V N.B. Palmer remained on station from September 28 (day 271) to October 23 (day 296) anchored to a floe composed of a mixture of thin and thick first-year ice (FY) with embedded thick multi-year ice (MY). During this time, the $R / V$ N.B. Palmer drifted within $69-71^{\circ} \mathrm{S}$ and $90-95^{\circ} \mathrm{W}$ (see Lewis et al., 2011). The drift was initially very intense to the East, due to a strong storm (max. hourly average wind speed $30 \mathrm{~m} / \mathrm{s}$ ). From days 277 to 285 , the Palmer drifted to the West, then the trajectory shifted back to the East until the end of the station. Experiments were conducted at several sites (Lewis et al., 2011), among which, two Belgian Biogeochemistry (BB) sites were sampled repeatedly from days 274 to 296 . The first site (Brussels) had average ice thickness of $0.59 \pm 0.04 \mathrm{~m}$ and snow depth of $0.09 \pm 0.05 \mathrm{~m}$. The second site (Liège) had thicker ice, typically around $1.2 \mathrm{~m}$ and deeper snow, on average $0.52 \pm 0.04 \mathrm{~m}$. Much thicker ice, including regions thicker than $5 \mathrm{~m}$ was found along transects elsewhere on the SIMBA floe (Lewis et al., 2011).

ISPOL (Hellmer et al., 2008) took place in the Western Weddell Sea in spring-summer 2004-2005. The R/V Polarstern remained on a 35-day long ice station from November 28, 2004 (day 337) until January 2, 2005 (day 368). The Polarstern was anchored to a floe composed of patches of thick and thin FY embedded with a matrix of second-year ice (SY) and drifted within $67-69^{\circ} \mathrm{S}$ and $54-56^{\circ} \mathrm{W}$. The drift was generally to the North with occasional diversions southward (Heil et al., 2008). Modal total thickness (e.g., snow+ice) ranged from $1.2-1.3$ to $2.4-2.9 \mathrm{~m}$ for FY and SY ice, respectively (Haas et al., 2008; Tison et al., 2008).

\subsection{Meteorological and radiation data}

SIMBA: Atmospheric and radiation data reported here for the SIMBA drifting station come from four different sources. The first data set (hereafter SHIP, capitalized for readability) consists of ship-based observations of wind speed and direction, temperature, relative humidity and radiation fluxes using the vessels' meteorological instruments. The thermometer and hygrometer were mounted at a height of $15 \mathrm{~m}$ above sea level, and the barometer was mounted at $30 \mathrm{~m}$ above sea level. The anemometers and radiometers were at $30.5 \mathrm{~m}$. Radiometers included a pyranometer ${ }^{1}$ for shortwave radiation $\left(F_{S W}, 0.3-3.0 \mu \mathrm{m}\right)$, a pyrgeometer ${ }^{2}$ for longwave $\left(F_{L W}, 4-50 \mu \mathrm{m}\right)$ radiation and a quantum scalar sensor ${ }^{3}$ for photosynthetically active radiation (PAR, 0.4-0.7 $\mu \mathrm{m}$ ) total quanta $\left(Q_{P A R}\right)$ (Morel and Smith, 1974) (see Appendix A for more details on definitions). Data cover days 266-301. All parameters apart from wind gusts were collected at 10 -s intervals and averaged over $1 \mathrm{~min}$. All fluxes in this paper are assumed positive from the atmosphere towards snow and ice.

The second data set consists of meteorological measurements performed on the sea ice (TOWER) adjacent to site Brussels. Data cover days 275-295. This short-term installation consisted of an aluminum tripod equipped with an eddy covariance system. This consisted of an ultra sonic anemometer ${ }^{4}$ and an open-path gas

\footnotetext{
${ }^{1}$ Precision Spectral Pyranometer (PSP), Eppley.

2 Precision Infrared Radiometer (PIR), Eppley.

${ }^{3}$ QSR-240 Quantum Scalar Reference Sensor, Biospherical instruments. The sensor probe is a sphere placed inside a black bowl-thus only collecting downward scalar irradiance. However, the spherical surface of the half-shaded probe $\left(2 \pi R^{2}\right)$ is twice the cross-sectional area of a cosine sensor $\left(\pi R^{2}\right)$. Hence, the measured value has to be divided by two in order to retrieve the scalar downward irradiance.

${ }^{4}$ Campbell Scientific Model CSAT3.
}

$\left(\mathrm{H}_{2} \mathrm{O}\right.$ and $\left.\mathrm{CO}_{2}\right)$ analyzer ${ }^{5}$ installed at a height of $2.45 \mathrm{~m}$. Wind speed $^{6}$ was measured at $2.75 \mathrm{~m}$, atop the tower, and a temperature and relative humidity probe ${ }^{7}$ was installed at $2.45 \mathrm{~m}$. High frequency eddy covariance data were measured at $20 \mathrm{~Hz}$, and hourly fluxes were computed during post-processing. The meteorological elements were logged at $3 \mathrm{~s}$ intervals, and saved as $30 \mathrm{~min}$ averages. TOWER and SHIP instruments were inter-calibrated (see Fig. 2). Firstly, due to the different sensor altitudes, the SHIP wind speed averaged 1.7 times that measured at the TOWER. Second, the SHIP temperature was $1{ }^{\circ} \mathrm{C}$ warmer than at the TOWER. The SHIP hygrometer did not operate for most of the cruise. Intercomparison between hygrometers from both sites after repair of the SHIP instrument showed very little difference (0-2\%).

A third data set (VISUAL) includes 282 hourly visual estimates of cloud fraction and snowfall made mostly during daylight hours, covering $52 \%$ of the total drifting station time. These data cover days 276-296.

Finally, albedo was estimated using a portable bidirectional pyranometer. ${ }^{8}$ Measurements of wavelength-integrated albedo were taken on two $25 \mathrm{~m}$ long lines with six points spaced $5 \mathrm{~m}$ apart on each line. These lines were each approximately $50 \mathrm{~m}$ from the two BB sites. An additional point was made immediately adjacent to each BB site. The two BB sites were each measured five times at regular intervals throughout the drifting station. Measurements showed albedo values typical for dry snow: 0.81 \pm 0.06 under clear skies and $0.85 \pm 0.03$ under cloudy skies. Those were consistent with the values of Brandt et al. (2005).

ISPOL: Atmospheric and radiation data for the ISPOL station come from the meteorological station referred to as AWI station (see Nicolaus et al., 2006, 2009). These data are independent of those from a meteorological mast on the sea ice (see Vihma et al., 2009). Incoming and reflected solar radiation fluxes were determined with pyranometers. ${ }^{9}$ Incoming and outgoing longwave radiations were also measured using two Eppley pyrgeometers. Air temperature, relative humidity and wind velocity were measured $2 \mathrm{~m}$ above the snow surface with an automatic weather station. All parameters apart from wind gusts, were measured at 10 -s intervals and averaged over 5 min periods by the data logger. Albedo was measured using the ratio of reflected and incoming SW and was found to be typical of wet snow. Using the cloud proxy defined in Appendix A and reprocessing Nicolaus et al.'s (2009) data we found an average albedo of $0.72 \pm 0.07$ under clear skies and of $0.78 \pm 0.06$ under cloudy skies.

\subsection{Reanalysis data}

The in situ data were compared to the NCEP/NCAR reanalyses (Kalnay et al., 1996) (see Table 2). For this we used NCEP's daily averages of 6 -h reanalyses on the $1.875 \times 1.875^{\circ}$ Gaussian grid. For both drifting stations, daily time series of reanalyzed atmospheric fields were extracted using values from the nearest grid point. The NCEP/NCAR reanalysis system assimilates - when available and after a quality check - wind components, air temperature, specific humidity and sea-level pressure (Parrish and Derber, 1992) from the Comprehensive Ocean-Atmosphere Data Set (COADS), which includes among others measurements made on ships and buoys. Hence, meteorological data from both $R / V$ Palmer and $R / V$ Polarstern were used in the NCEP/NCAR reanalysis. NCEP data are easily accessible and run through the present date, hence most sea ice models use them as forcing.

\footnotetext{
${ }^{5}$ LI-COR LI7500.

${ }^{6}$ The anemometer on the tower is an RMYOUNG Model 05106.

7 Vaisala Model HMP 45212.

${ }^{8}$ PSP, Eppley.

${ }^{9}$ Kipp \& Zonen CM22.
} 
SIMBA

ISPOL

Air temperature
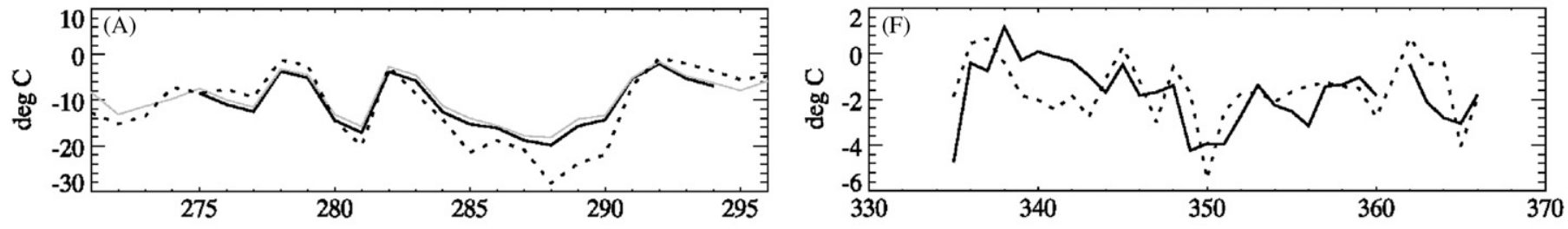

Specific humidity
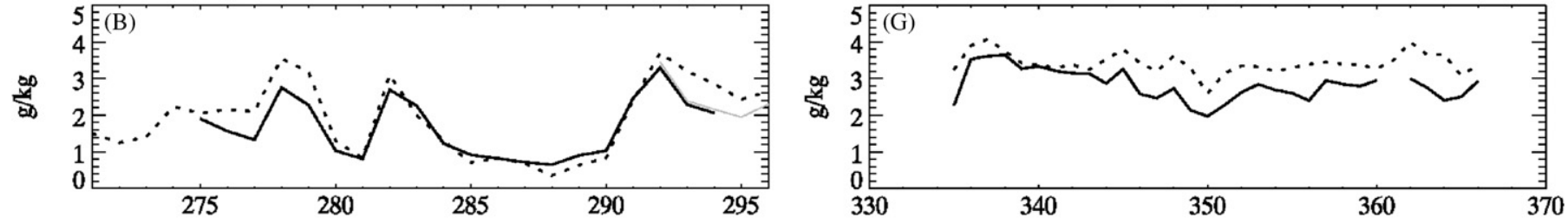

Wind speed
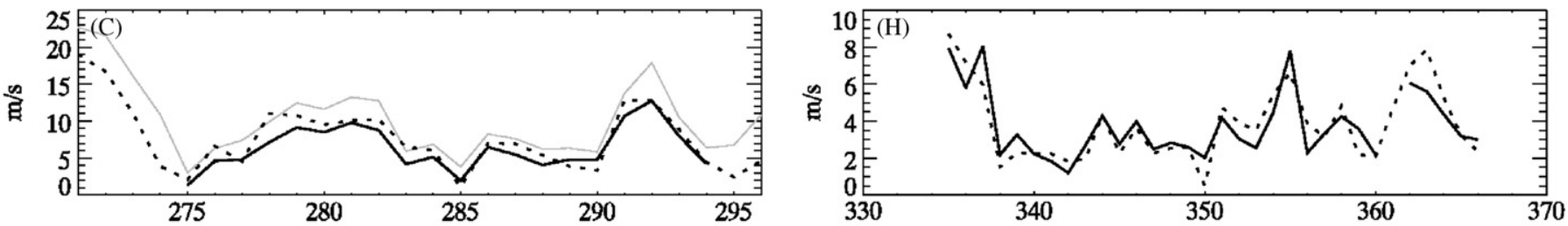

Wind direction

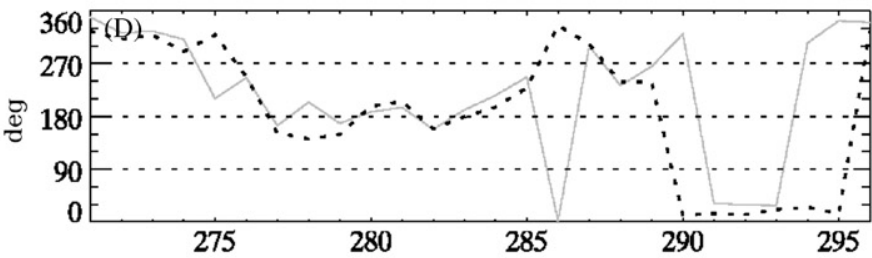

Cloud fraction
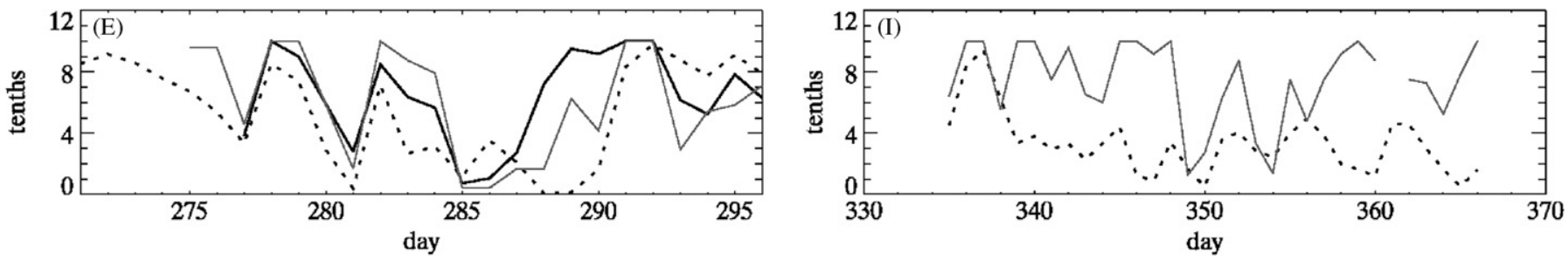

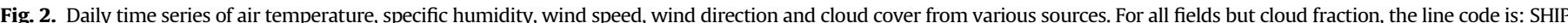

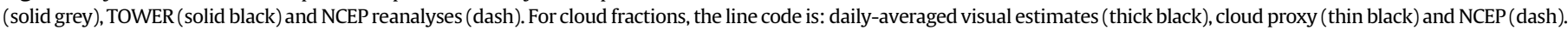
Wind direction increases from $0^{\circ}$ (winds blowing from the East) couterclockwise, hence $0^{\circ}$ and $360^{\circ}$ represent the same direction. See text for details on missing fields.

\section{Meteorology from observations and reanalysis data}

\subsection{Observations}

The weather at SIMBA (see Fig. 2) was characterized by typical spring conditions. The air temperature averaged $-9.8 \pm 5.2^{\circ} \mathrm{C}$ and hourly wind speed was $10.1 \pm 5.9 \mathrm{~m} / \mathrm{s}$ with a maximum of $30 \mathrm{~m} / \mathrm{s}$ while the mean specific humidity $(q)$ was $1.7 \pm 0.9 \mathrm{~g} / \mathrm{kg}$. Weather variability was associated with changes in the wind direction and the continental/oceanic origin of air masses. Under northerly winds, warm (from -5 to $0{ }^{\circ} \mathrm{C}$ ) wet $(q \sim 2.5 \mathrm{~g} / \mathrm{kg})$ oceanic air was advected toward the SIMBA floe. Under southerly winds, cold (from -20 to $\left.-10{ }^{\circ} \mathrm{C}\right) \operatorname{dry}(q \sim 1 \mathrm{~g} / \mathrm{kg})$ continental air was brought to the station. Intermediate regimes were found when the winds arrived from other directions. Visual observations account for nine snowfall events, three of which were classified as heavy (October $10,18-19,22-23)$, in good accord with observations from automated shipboard precipitation monitoring (Leonard and Cullather, 2008). Clear skies were mostly present under dry and cold weather conditions. Average daily cloud fraction from VISUAL estimates was $6.5 \pm 3.8$ tenths. Forty eight percent of these observations showed cloudy skies (defined as a visual cloud fraction $>3 / 10$ ). The atmospheric transmissivity (ratio of surface to top-of-atmosphere incoming SW radiation) was $0.49 \pm 0.20$. A daily cloud fraction proxy was constructed using the hourly anomalies of radiative fluxes (see Appendix B). The daily cloud proxy was on average $5.7 \pm 3.4$ tenths from October 1 to October 25. The cloud fraction proxy is 0.66 tenths lower than VISUAL record and the correlation coefficient between observed and proxy cloud fractions is 0.78 .

At ISPOL, the weather was milder. The air temperature averaged $-1.9 \pm 2.0^{\circ} \mathrm{C}$, wind speeds were $3.7 \pm 2.0 \mathrm{~m} / \mathrm{s}$ with a hourly maximum up to $11 \mathrm{~m} / \mathrm{s}$ while the mean specific humidity was 2.8 $\pm 0.5 \mathrm{~g} / \mathrm{kg}$. Warm northerly winds were the most common and 
Table 2

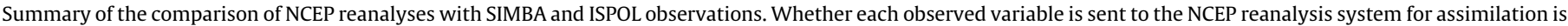

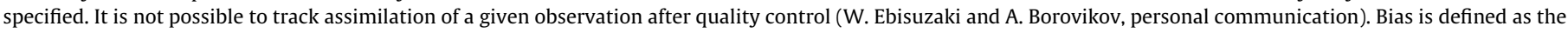
mean of the differences between two time series. RMS is the root-mean-square difference and c.c. is the correlation coefficient.

\begin{tabular}{|c|c|c|c|c|}
\hline Variable & Units & $\begin{array}{l}\text { Sent to NCEP? } \\
\text { SIMBA-ISPOL }\end{array}$ & $\begin{array}{l}\text { Bias } \pm \text { RMS (c.c.) } \\
\text { SIMBA }\end{array}$ & $\begin{array}{l}\text { Bias } \pm \text { RMS (c.c.) } \\
\text { ISPOL }\end{array}$ \\
\hline Air temperature & ${ }^{\circ} \mathrm{C}$ & yes-yes & $-1.2 \pm 3.8(0.94)$ & $0.1 \pm 1.4(0.44)$ \\
\hline Wind speed & $\mathrm{m} / \mathrm{s}$ & yes $^{\mathrm{a}}-\mathrm{yes}^{\mathrm{a}}$ & $0.8 \pm 1.2(0.93)$ & $0.1 \pm 1.0(0.88)$ \\
\hline Wind direction & deg & yes $^{\mathrm{a}}-\mathrm{yes}^{\mathrm{a}}$ & $-16.9 \pm 123(0.35)$ & n.a \\
\hline Specific humidity & $\mathrm{g} / \mathrm{kg}$ & partly-yes & $0.2 \pm 0.4(0.95)$ & $0.6 \pm 0.3(0.65)$ \\
\hline Rel. hum. (ice) & $\%$ & partly-yes & $19 \pm 16(-0.21)$ & $18 \pm 7(-0.20)$ \\
\hline Sea-level pres. & $\mathrm{mb}$ & yes-yes & $0.6 \pm 5.4(0.95)$ & n.a. \\
\hline Cloud fraction & tenths & no-no & $-1.6 \pm 3.3(0.46)$ & n.a. \\
\hline SW rad. (down) & $\mathrm{W} / \mathrm{m}^{2}$ & no-no & $42.8 \pm 50.1(0.63)$ & $109.4 \pm 121.4(0.07)$ \\
\hline LW rad. (down) & $\mathrm{W} / \mathrm{m}^{2}$ & no-no & $-20.3 \pm 50.8(0.86)$ & $-44.8 \pm 44.7(0.57)$ \\
\hline
\end{tabular}

${ }^{\text {a }}$ Wind velocity vector components are assimilated.
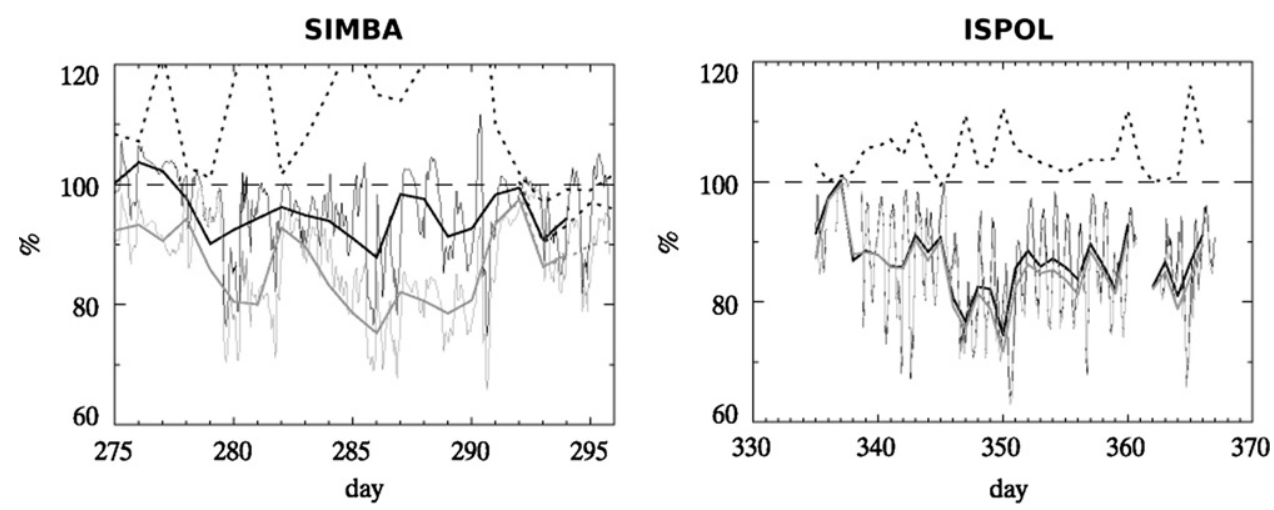

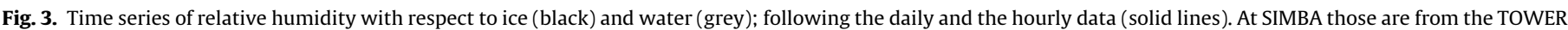

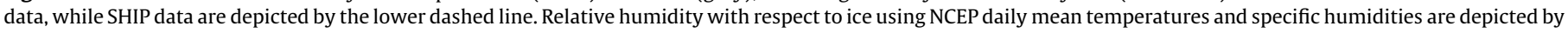
the upper dashed line.

maintained relatively high temperatures while short southerly wind episodes or surface-based inversions were associated with temperatures below $-5{ }^{\circ} \mathrm{C}$ (Vihma et al., 2009). Cloud fraction data are unavailable for ISPOL, but qualitative observations suggest prevailing overcast skies with only a few episodes of clear skies associated to continental winds (Nicolaus et al., 2009). The cloud fraction proxy $(7.4 \pm 2.6$ tenths), supports the latter. The atmospheric transmissivity was slightly higher than in SIMBA $(0.53 \pm 0.17)$. See Nicolaus et al. (2009) and Vihma et al. (2009) for more information on the meteorological conditions at ISPOL.

The TOWER relative air humidity at SIMBA (relative to ice) was on average $95 \%$, with frequent values over $100 \%$, indicating permanent near-saturation. This is consistent with previous studies made over Arctic sea ice and over fall-winter Antarctic sea ice (Andreas et al., 2002). In contrast, air hardly reached water vapour saturation with respect to water and ice at ISPOL, with relative humidity averaging $87 \%$ (see Fig. 3 ). It may seem surprising that while the specific humidity was larger at ISPOL than SIMBA, the relative humidity was lower. This is because the larger specific humidity at ISPOL was more than offset by the effect of higher ISPOL temperatures on water vapour saturation pressure. A firstorder analysis of the partial derivatives of relative humidity suggests that low relative humidities at ISPOL are in large part due to low air specific humidity. Over reasonable changes in air temperature, specific humidity and sea-level pressure, only a specific humidity change could provide enough humidity to bring the air to saturation. Finally, there is a clear diurnal cycle in relative humidity during ISPOL with lower values in the afternoon, driven by the diurnal cycle in air temperature (see Vihma et al., 2009, for a discussion), while such a diurnal cycle is not as obvious at SIMBA.

\subsubsection{Comparison with NCEP reanalyses}

Comparison between in situ data and NCEP reanalyses indicates the following. The values hereafter referred to as errors are average differences between daily mean NCEP and in situ values when the ship was in ice-covered areas and when data were available. The error in air temperature is $-1.2 \pm 3.8{ }^{\circ} \mathrm{C}$ at SIMBA and $0.1 \pm 1.4{ }^{\circ} \mathrm{C}$ at ISPOL and can be quite large over relatively short time periods (e.g., days 285-290 at SIMBA). The error in specific humidity is relatively small at SIMBA $(0.2 \pm 0.4 \mathrm{~g} / \mathrm{kg}$, TOWER data) and is larger at ISPOL $(0.6$ $\pm 0.3 \mathrm{~g} / \mathrm{kg}$ ). The error in relative humidity is larger, with differences of $19 \pm 16 \%$ at SIMBA and $18 \pm 7 \%$ at ISPOL. The error in relative humidity is larger than in specific humidity because relative humidity incorporates errors in both specific humidity and air temperature.

Wind speed is more difficult to analyze because at SIMBA, the TOWER, NCEP and SHIP estimates correspond to different altitudes and because wind speed and direction vary at higher frequency than the averaging windows used here. NCEP winds combine information from the atmospheric model's dynamics, direct observations using the assimilation scheme. A first look at Fig. 2 indicates that the NCEP winds almost always fall between the (smaller) TOWER and (larger) SHIP values. For cases in which the atmospheric boundary layer is neutrally stable (Blackadar, 1962), the wind speed increases with altitude following:

$$
\frac{W(z)}{W\left(z_{\text {tow }}\right)}=\frac{\ln \left(\frac{z}{z_{0}}\right)}{\ln \left(\frac{z_{\text {tow }}}{z_{0}}\right)},
$$

where $z_{\text {tow }}$ is the height of the TOWER anemometer $(2.75 \mathrm{~m}), z$ is the altitude of any other estimate (SHIP or NCEP) and $z_{0}$ is the 
roughness length. While atmospheric conditions over sea ice are typically not stable due to the presence of leads (Pinto et al., 1995) and blowing snow (Déry and Tremblay, 2004), the $30 \mathrm{~m}$ offset between the TOWER and SHIP measurement heights means that the NCEP $\sigma-1$ winds follow this equation to a first approximation and there is no significant bias in that data. The average roughness length $z_{0}$ determined using the eddy correlation system on the TOWER for the month long SIMBA drift was $5.6 \pm 7.7 \times 10^{-4} \mathrm{~m}$. This value was reduced to an average of $4.9 \times 10^{-4} \mathrm{~m}$ under conditions of high surface shear $\left(u^{*}>0.3\right)$, indicating smoothing of the rough sea ice surface by drifting and blowing snow (contrary to Andreas et al., 2010). Both SHIP and NCEP data follow Eq. (1) within the range of errors, hence we cannot find a significant bias in NCEP wind magnitude. During the ISPOL drifting station, there was only one wind sensor at $2 \mathrm{~m}$ height. No significant bias in wind speed was found when comparing this data to NCEP.

Time series of wind direction in the NCEP data set are in general agreement with SHIP observations at SIMBA. There are significant discrepancies, though, leading to a bias of $16.9 \pm 123^{\circ}$ with maxima within $60-90^{\circ}$.

Errors in observed/proxy cloud fractions are too large for an accurate comparison with NCEP data. Qualitatively, it seems that, at the SIMBA location, NCEP reanalyses capture the clear-cloud sky contrast in some cases. One remarkable episode of NCEP misbehavior was the stratus clouds observed during the cold period from 14 to 17 October (days 287-290), while NCEP predict no clouds during that period. The cloud fraction proxy based on radiation anomalies was likewise unable to reproduce high cloud fraction during that period. Cloud fractions at ISPOL seem largely underestimated by NCEP compared to cloud fraction proxy. Observation log books (Nicolaus et al., 2009) and radiation data (see next section) also suggested prevailing overcast conditions during ISPOL.

\section{Radiation from observations, reanalyses and parameterizations}

\subsection{Observations}

At SIMBA, SHIP radiation data indicate that the mean hourly solar radiation flux $F_{S W}$ was $118 \pm 143 \mathrm{~W} / \mathrm{m}^{2}$. The mean number of photons in the visible spectrum $\left(Q_{P A R}\right)$ was $294 \pm 340 \mu \mathrm{E} / \mathrm{m}^{2} / \mathrm{s}$ and the mean $L W$ radiation flux $F_{L W}$ was $229 \pm 46 \mathrm{~W} / \mathrm{m}^{2}$. During ISPOL, $F_{S W}$ was $280 \pm 240 \mathrm{~W} / \mathrm{m}^{2}$ and mean $F_{L W}$ was $276 \pm 26 \mathrm{~W} / \mathrm{m}^{2}$. $Q_{P A R}$ was not observed during ISPOL.

Time series of daily solar radiation during SIMBA (see Fig. 4, panel a, solid line) feature a long-term increase of $3.5 \mathrm{~W} / \mathrm{m}^{2} / \mathrm{d}$, which is due to the increasing solar angle associated with the advance of spring. $Q_{P A R}$ shows a similar increasing trend (Fig. 5). Time series of longwave radiation had no significant trend (Fig. 6). As ISPOL occurred near the solar maximum, no trend is detectable in either shortwave or longwave radiation. Note that there were no PAR measurements at ISPOL. At both stations, the day-to-day variability in both SW and LW fluxes was driven by atmospheric state, in particular by clouds. At both stations, $F_{S W}$ (and $Q_{P A R}$ at SIMBA) showed a marked diurnal cycle, while $F_{L W}$ did not.

The mean diurnal cycles of radiative fluxes for clear and cloudy skies were computed using observed (proxy) cloud fraction at SIMBA (ISPOL), see Fig. 7. Cloud radiative forcing was computed by taking the mean difference between the cloud sky and the clear sky diurnal cycles. Cloud SW forcing was equal to -79 and $-99 \mathrm{~W} / \mathrm{m}^{2}$, while LW forcing equalled 78 and $52 \mathrm{~W} / \mathrm{m}^{2}$ at SIMBA and ISPOL, respectively.

\subsection{Reanalysis and parameterizations}

As radiation measurements are rare, sea ice models use indirect reconstructions of atmospheric radiative forcing. Here we assess three different procedures for computing radiation fluxes using drifting station radiation data.

The most basic method employed in sea ice models and evaluated here is to use the value provided in atmospheric reanalyses data sets such as NCEP-NCAR ${ }^{10}$ (Kalnay et al., 1996). These typically consist of daily values of $F_{S W}$ and $F_{L W}$, available in this case on a $2^{\circ}$ by $2^{\circ}$ grid with global coverage and on a daily basis.

A second method is to combine empirical parameterizations with meteorological variables that are more frequently available than radiation fluxes themselves such as temperature, humidity or cloud fraction. The parameterizations for downwelling long- and shortwave fluxes used here include those recommended by Key et al. (1996) who compared several different parameterization schemes with measured fluxes obtained over several weeks in different Arctic regions.

Finally, we assess the method proposed by Goosse (1997) and Timmermann et al. (2005) to force the NEMO-LIM ice-ocean model (Madec, 2008; Vancoppenolle et al., 2009). Arguing that there are problems in cloud fraction and humidity from the NCEP reanalyses, Goosse (1997) suggests to use a combination of, on the one hand, daily NCEP air temperatures, wind speed and pressure - for which NCEP reanalyses seem reasonable - and of monthly mean climatologies (referred to as CLIM in the following Tables) of cloud fraction (Berliand and Strokina, 1980), relative humidity (Trenberth et al., 1989) and cloud optical depth (Chou and Curran, 1981). While this method was designed to reduce the bias in the radiation forcing, it deteriorates the spatio-temporal variability in the radiation field.

\subsection{Shortwave radiation}

Computation methods: In many ice-ocean models, the strategy of Parkinson and Washington (1979) for computing the downwelling shortwave radiation flux is used. The latter uses Zillman's (1972) equation for clear skies and applies a factor to account for cloudy skies:

$F_{S W}^{c l r}=\frac{S_{0} \cos ^{2} Z}{1.085 \cos Z+10^{-3} e(2.7+\cos Z)+0.10}$,

$F_{S W}=F_{S W}^{c l r}\left(1-0.6 c^{3}\right)$.

$F_{S W}^{c l r}$, and $F_{S W}$ are the downwelling shortwave radiative fluxes for clear skies and all skies, respectively. Other variables and parameters include the solar zenith angle $Z$, computed as a function of latitude, day and hour using astronomical equations (see, e.g., Peixoto and Oort, 1992), the solar constant $S_{0}=1368 \mathrm{~W} / \mathrm{m}^{2}$, the near-surface water vapour pressure $e$ (in millibars) and the fractional cloud cover $c$. Based on surface meteorology observations from $45 \mathrm{yr}$ of Soviet drifting station in the Arctic Ocean, Lindsay (1998), following Key et al. (1996) suggests that the parameterization of Shine (1984) is better suited for polar regions since it accounts for multiple cloud-to-ice reflections at low solar angles:

$F_{S W}^{c l r}=\frac{S_{0} \cos ^{2} Z}{1.2 \cos Z+10^{-3} e(1+\cos Z)+0.0455}$,

$F_{S W}^{c l d}=\frac{(53.5+1274.5 \cos Z) \sqrt{\cos Z}}{1+0.139(1-0.9345 \alpha) \tau}$,

\footnotetext{
${ }^{10} \mathrm{NCEP}=$ National Center for Environmental Prediction. NCAR=Nationa Center for Atmospheric Research.
} 
SIMBA

Time series of daily values
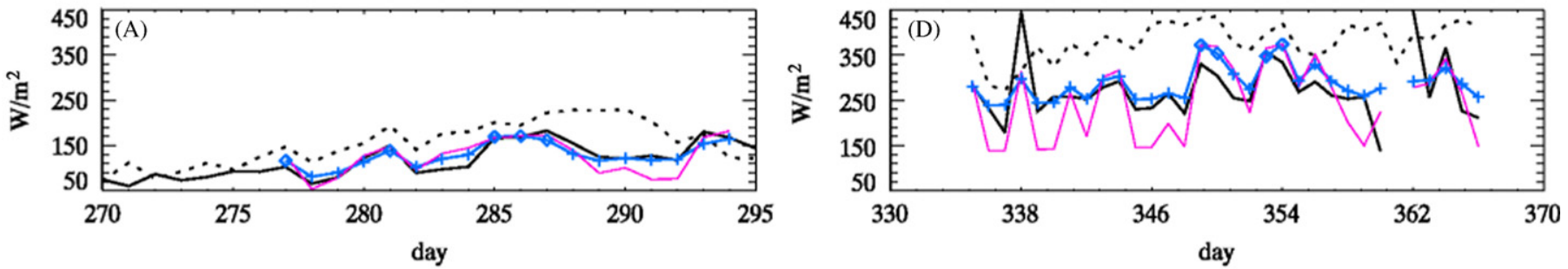

Shine - Obs (clear sky)
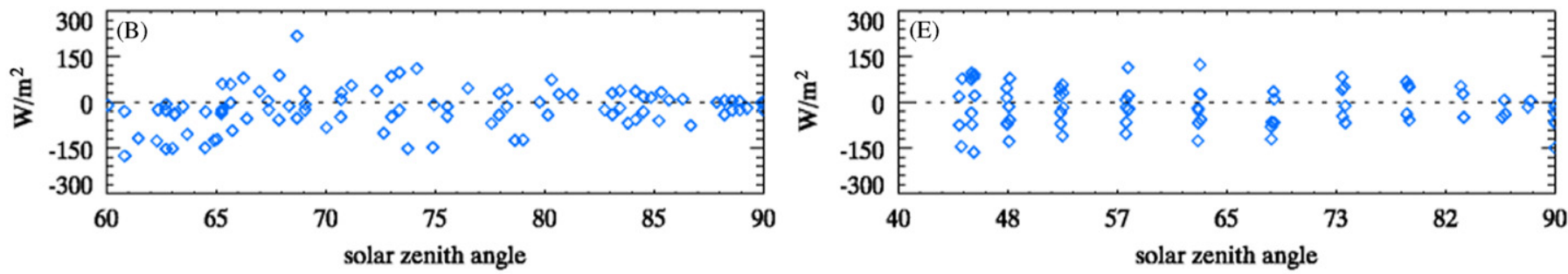

Shine - Obs (cloud sky)
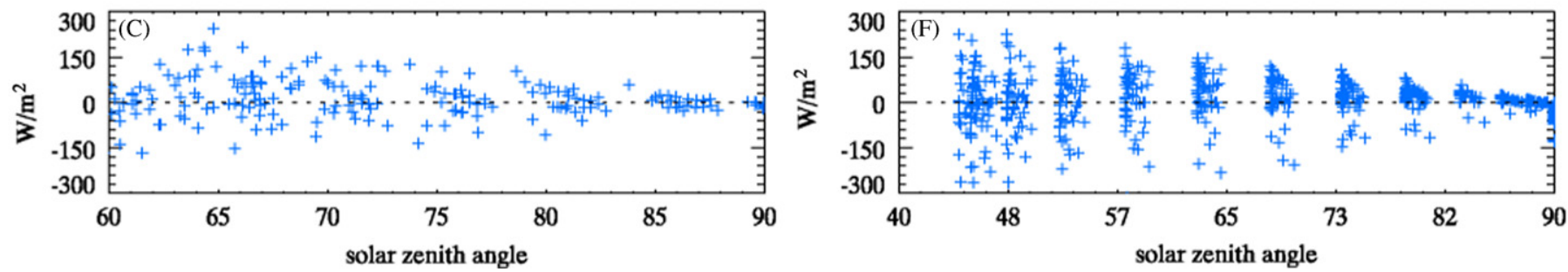

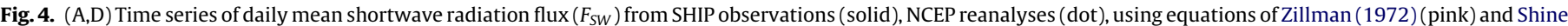

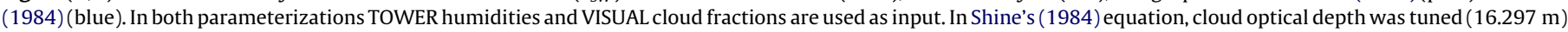

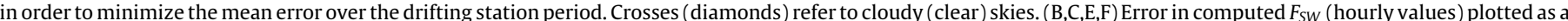

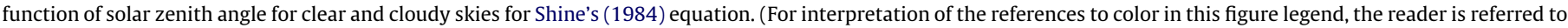
the web version of this article.)
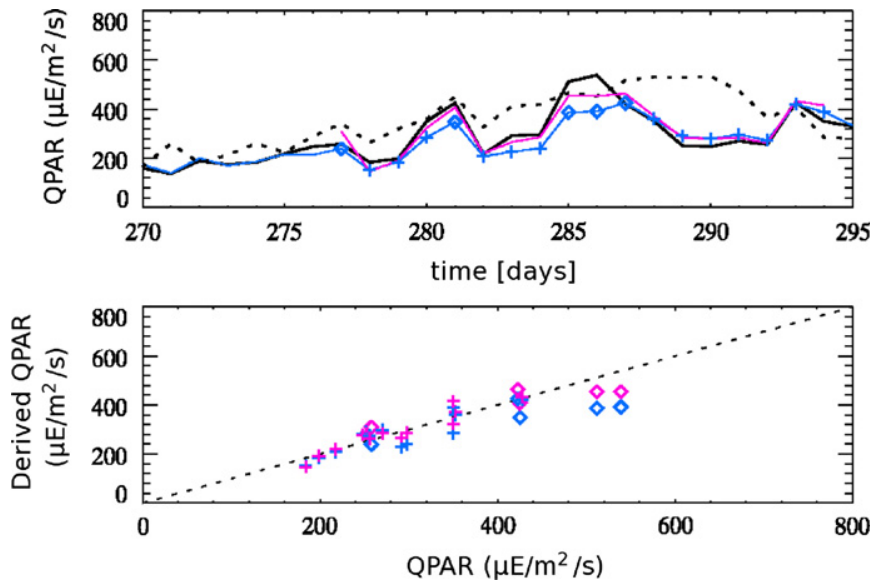

Fig. 5. (A) Time series of daily mean $Q_{P A R}$ from ship observations (solid black) and reconstructions: NCEP $F_{S W}$ multiplied by 2.33 (dots) and the SHIP $F_{S W}$ multiplied by 2.33 (blue); using Eq. 9 with VISUAL cloud fractions and SHIP $F_{S W}$ as an input (pink). Crosses (diamonds) refer to cloudy (clear) skies. (B) Reconstructed values plotted versus observations. Color coding as in (a). (For interpretation of the references to color in this figure legend, the reader is referred to the web version of this article.)

$F_{S W}=(1-c) F_{S W}^{c l r}+c F_{S W}^{c l d}$

in which $F_{S W}^{c l d}$ is the downwelling shortwave radiative flux for cloudy skies, $\alpha$ is the surface albedo and $\tau$ the cloud optical depth. The inclusion of albedo in this formulation reflects its importance for multiple reflections. Therefore, it should be the average albedo of a wide area around the study site. Following in situ observations at SIMBA, we take $\alpha=0.85$.

Results: In Fig. 4 (panel A) and Table 3, several computational methods for $F_{S W}$ are evaluated against observations. Methods of computation include direct use of NCEP reanalyses and the radiation parameterizations of Zillman (1972) and Shine (1984) forced with cloud parameters and humidity from (i) drifting station observation data, (ii) NCEP reanalyses and (iii) climatologies of Berliand and Strokina (1980), Chou and Curran (1981) and Trenberth et al. (1989), respectively.

Among these methods for SW radiation calculation, the unaltered NCEP forcing has the largest biases compared to observations (43-109 W/m $/ \mathrm{m}^{2}$ ). Reconstructions of $F_{S W}$ from Shine's (1984) parameterization forced by in situ cloud fractions and humidities and using $\tau=16.297 \mathrm{~m}$ were closest to observations. As no estimate of $\tau$ is available, this value was adjusted to minimize the bias between observed and computed SW flux at SIMBA $\left(<10^{-3} \mathrm{~W} / \mathrm{m}^{2}\right)$. Unfortunately, this $\tau$ value was tuned for clouds that were different from ISPOL and induces a higher bias $\left(14 \mathrm{~W} / \mathrm{m}^{2}\right)$. The bias in computed SW increases to $17-62 \mathrm{~W} / \mathrm{m}^{2}$ using $\tau=5.6 \mathrm{~m}$ (Chou and Curran, 1981 ) and the same cloud fractions and humidities. In comparison, the time series of $F_{S W}$ computed using the formulation after Zillman (1972) with the same atmospheric data have lower biases ( -4 and $-25 \mathrm{~W} / \mathrm{m}^{2}$ ) but those results have lower correlations with the observed time series. As in Key et al. (1996), an error analysis of 
Time series of daily values
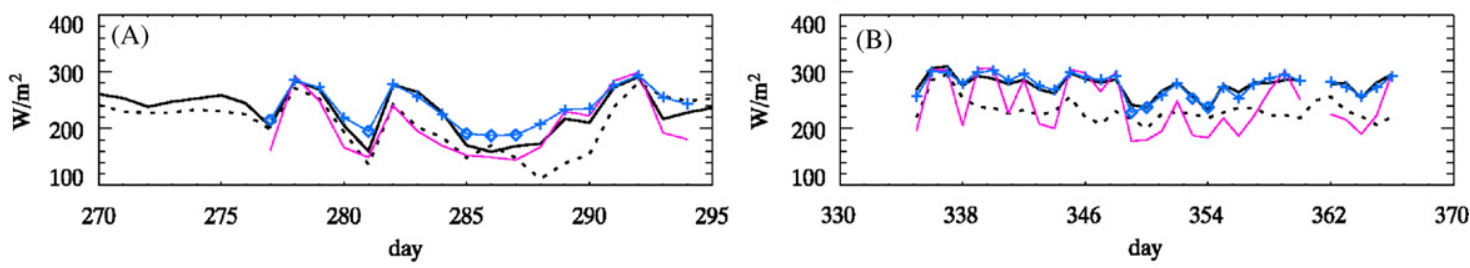

Formula vs obs.
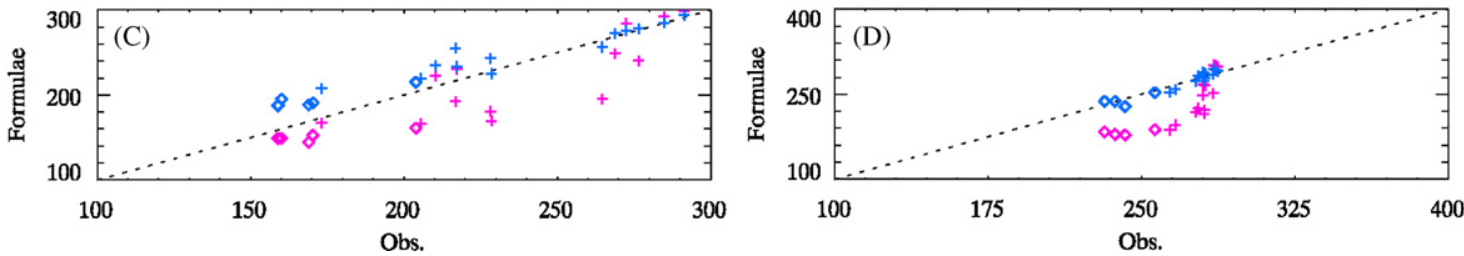

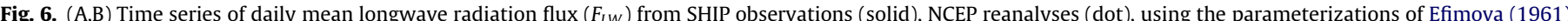

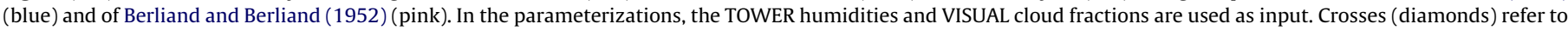

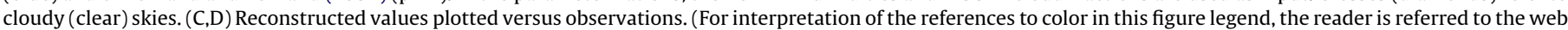
version of this article.)
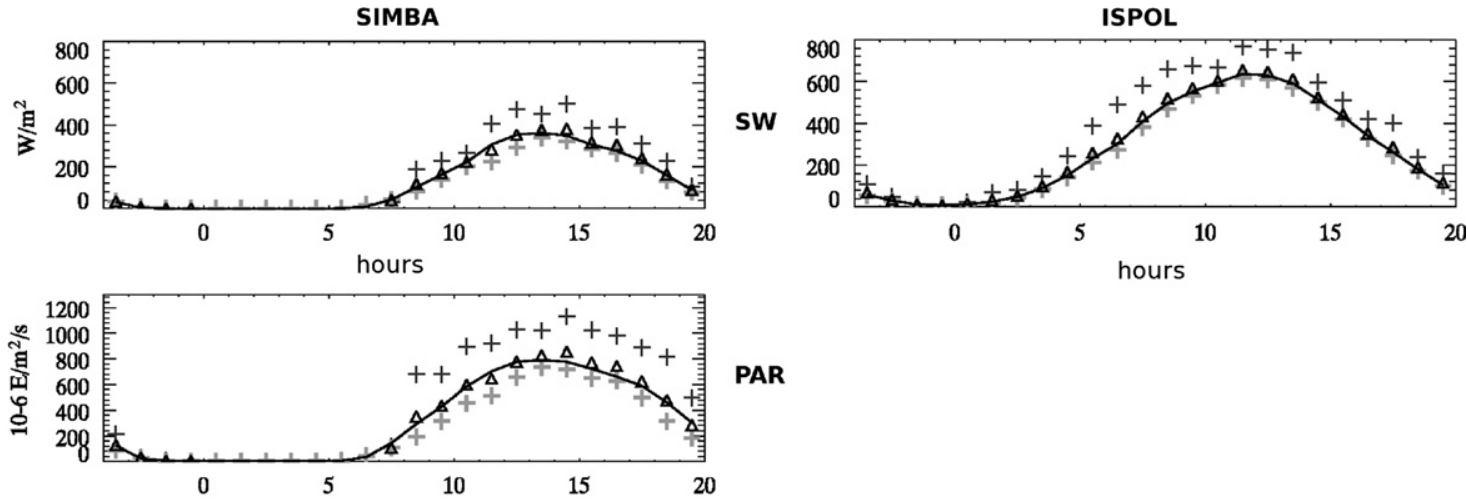

PAR
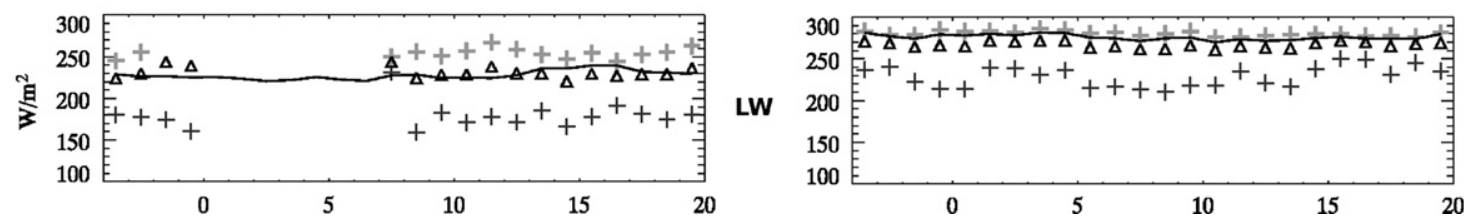

Fig. 7. Mean diurnal cycle of $(A)$ shortwave, (B) photosynthetically active radiation $\left(Q_{P A R}\right)$ and $(C)$ longwave fluxes during the drifting stations period, hourly averages for each hour $h$ : all skies (solid line), clear skies $\left(F^{c l r}(h)\right.$, black crosses), cloudy skies $\left(F^{c l d}(h)\right.$, grey crosses). Weighted averages using visual (proxy) cloud fraction at SIMBA (ISPOL) $c(h)$ : $[1-c(h)] F^{c l r}(h)+c(h) F^{c l d}(h)$ are also shown for indication (triangles).

hourly averaged values (see Fig. 4, panels B, C, E, F) suggests that the biases using Shine's (1984) equation are largest at low solar angles under cloudy skies. This was also found true for Zillman's (1972) parameterization.

Combinations of radiation parameterizations with atmospheric data from NCEP reanalyses or climatologies lead to lower biases than the NCEP $F_{S W}$ time series alone (see Table 3). Using climatologies reduces the bias compared to NCEP but slightly worsens the result in terms of correlations. Using climatologies of atmospheric data, Zillman's (1972) equation has biases that are significantly smaller $\left(22-29 \mathrm{~W} / \mathrm{m}^{2}\right)$ than Shine's (1984) parameterization $\left(28-67 \mathrm{~W} / \mathrm{m}^{2}\right)$, because the latter appears to contain an improper optical depth.

\subsection{Photosynthetically active radiation}

Photosynthetically active radiation is not a physical forcing of sea ice models. However, it is an essential forcing of ice ecosystem models which are on the way of being included in future sea ice models (Nishi and Tabeta, 2008; Tedesco, 2009; Vancoppenolle et al., 2010).

Computation methods: As the visible light is entirely included in the shortwave spectrum, it is not surprising to find a close connexion between $F_{S W}$ and $Q_{P A R}$. Indeed, they are highly correlated (c.c. $=0.96$ ) and the observed ratio $Q_{P A R} / F_{S W}$ is 2.33 for standard units (W/m $/ \mathrm{m}^{2}$ and $\mu \mathrm{E} / \mathrm{m}^{2} / \mathrm{s}$ ). As $Q_{P A R}$ is not often measured, it may be useful for biochemical models to express the latter by the means of other well-known quantities. Typically, a simple linear relation between $Q_{P A R}$ and $F_{S W}$ is used in models of ocean biogeochemistry (see, e.g., Aumont et al., 2003; Pasquer et al., 2005):

$Q_{P A R}=2.33 \times F_{S W}$.

This value can be understood as follows. The photosynthetically active radiation over shortwave ratio can be reformulated by

$\frac{Q_{P A R}}{F_{S W}}=\frac{Q_{P A R}}{F_{P A R}} \frac{F_{P A R}}{F_{S W}}$, 
Table 3

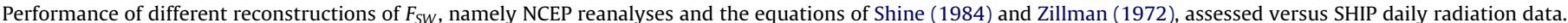

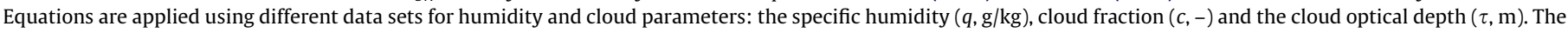

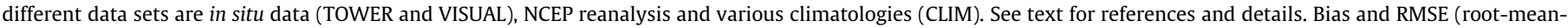
square error) values are in $\mathrm{W} / \mathrm{m}^{2}$. c.c. is the correlation coefficient.

\begin{tabular}{|c|c|c|c|c|c|c|c|}
\hline ID & Comput. meth. & $q$ & $c$ & $\tau$ & Bias & RMSE & c.c. \\
\hline \multicolumn{8}{|c|}{ SIMBA } \\
\hline 1 & NCEP & n.a. & n.a. & n.a. & 42.8 & 50.1 & 0.63 \\
\hline 2 & Shine (1984) & TOWER & VISUAL & 16.297 & 0.0005 & 12.4 & 0.92 \\
\hline 3 & Shine (1984) & TOWER & VISUAL & CLIM (5.6) & 16.6 & 19.9 & 0.92 \\
\hline 4 & Shine (1984) & NCEP & NCEP & CLIM (5.6) & 33.3 & 35.5 & 0.61 \\
\hline 5 & Shine (1984) & CLIM (1.8) & CLIM (0.66) & CLIM (5.6) & 28.3 & 34.5 & 0.55 \\
\hline 6 & Zillman (1972) & TOWER & VISUAL & n.a. & -3.9 & 18.5 & 0.79 \\
\hline 7 & Zillman (1972) & NCEP & NCEP & n.a. & 18.1 & 33.7 & 0.57 \\
\hline 8 & Zillman (1972) & CLIM (1.8) & CLIM (0.66) & n.a. & 21.8 & 30.7 & 0.58 \\
\hline \multicolumn{8}{|c|}{ ISPOL } \\
\hline 1 & NCEP & n.a. & n.a. & n.a. & 109.4 & 121.4 & 0.07 \\
\hline 2 & Shine (1984) & TOWER & VISUAL & 16.297 & 14.4 & 38.6 & 0.57 \\
\hline 3 & Shine (1984) & TOWER & VISUAL & CLIM (5.6) & 62.2 & 77.2 & 0.51 \\
\hline 4 & Shine (1984) & NCEP & NCEP & CLIM (5.6) & 88.9 & 102.3 & 0.009 \\
\hline 5 & Shine (1984) & CLIM (1.8) & CLIM (0.66) & CLIM (5.6) & 67.3 & 83.5 & 0.08 \\
\hline 6 & Zillman (1972) & TOWER & VISUAL & n.a. & -25.1 & 59 & 0.62 \\
\hline 7 & Zillman (1972) & NCEP & NCEP & n.a. & 73.7 & 90.7 & 0.13 \\
\hline 8 & Zillman (1972) & CLIM (1.8) & CLIM (0.66) & n.a. & 29.3 & 58.8 & 0.06 \\
\hline
\end{tabular}

where the quanta-energetic ratio $Q_{P A R} / F_{P A R}$ is $4.6 \pm 0.3 \mu \mathrm{E} / \mathrm{W} / \mathrm{s}$ based on near-surface spectral irradiance measurements (Morel and Smith, 1974). The SW-PAR energetic $F_{P A R} / F_{S W}$ ratio on the right-hand side has been estimated with a radiative transfer model to be within $0.45-0.50$ (Frouin and Pinker, 1995). Those two values suggest the range $2.08-2.33$ for the ratio $Q_{P A R} / F_{S W}$.

However, because clouds change the spectral distribution of solar radiation, a smaller portion of the solar spectrum lies in the visible band, when the sky is cloudy (see Fig. 8, panel A). Hence, based on SHIP data, we propose a more complex relation involving cloud fraction $c$ :

$Q_{P A R}=c A F_{S W}+(1-c)\left(B F_{S W}+D \sqrt{F_{S W}}\right)$.

A chi-square fit based on SHIP $F_{S W}$ and interpolated VISUAL cloud fraction estimates $C_{v}$ (see Appendix B) over the SIMBA drifting station period lead to $A=2.23, B=0.073$ and $D=34.74$ for standard units. The regression (see Fig. 8 , panel $\mathrm{B}$ ) produces a comparatively better reconstruction of the time series of hourly values $Q_{P A R}$. Unfortunately, we have no data at ISPOL to validate this regression.

Results: Now, we investigate how those parameterizations perform as forcings for ice-ocean models. Daily time series of $Q_{P A R}$, computed using Eqs. (7) and (9) with in situ SHIP and VISUAL $F_{S W}$ and $c$ data, over the drifting station period are compared (Fig. 5). The results of the same procedure applied to NCEP and climatological data as well as climatolgies (Table 4) first show that the complex regression, forced using in situ SHIP and VISUAL data (9) exhibits best agreement with observed daily $Q_{P A R}$, with practically no bias and high correlation (0.96). The more simple linear relation ( 7 ) features a bias within $10 \%$ and relatively high correlation (0.86).

However, when applied to radiative and cloud fraction data available globally and hence usable in ice-ocean models, no parameterization is able to reproduce $Q_{P A R}$ with high fidelity. Since they already contain large errors, the NCEP values of shortwave fluxes and cloud cover, combined with the linear parameterization lead to the largest biases (34-38\%). Lower biases (21-24\%) are obtained using monthly climatologies of cloud fraction and shortwave radiation from Zillman's (1972) equation, which is itself forced by monthly climatologies of humidity and cloud fraction. In
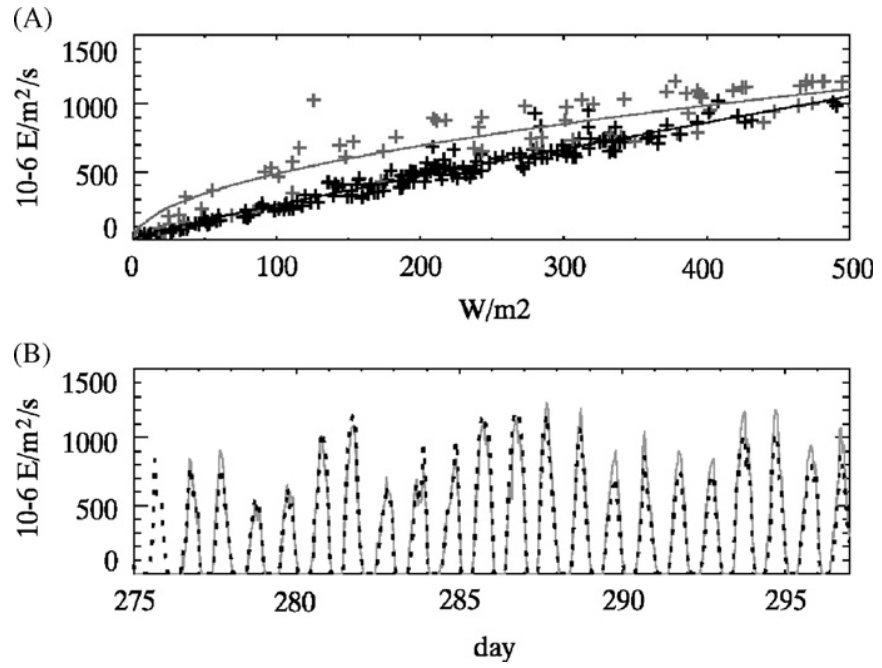

Fig. 8. (A) SHIP hourly values of $Q_{P A R}$ plotted as a function of $F_{S W}$, over the SIMBA drifting station (crosses) for clear skies (grey) and overcast skies (black). Sky classification is based on the cloudiness binary index $C_{i v}$ (see Appendix B). Corresponding regressions are indicated by solid lines. (B) Reconstructed time series of $Q_{P A R}$ using $F_{S W}$ and VISUAL cloud fraction $C_{v}$ time series using Eq. (9).

\section{Table 4}

Performance of two different reconstructions of $P A R$, namely multiplication of $F_{S W}$ by 2.33 , and the more complex relation (Eq. 9) in which PAR is computed as a function of $F_{S W}$ and cloud fraction. Equations are applied using different data sets for cloud fraction and $F_{S W}$. The latter are: in situ data (TOWER and VISUAL), NCEP reanalyses, climatologies (CLIM) as well as the $F_{S W}$ reconstruction using the equation of Zillman (1972) (see Table 3, ID8). Bias and RMSE (root-mean-square error) values are in $\mu \mathrm{E} / \mathrm{m}^{2} /$ s. c.c. is the correlation coefficient.

\begin{tabular}{llllrrr}
\hline ID & Comput. meth. & $F_{S W}$ & $c$ & \multicolumn{1}{c}{ Bias } & RMSE & c.c. \\
\hline 1 & $2.33 \times F_{S W}$ & SHIP & n.a. & -25.3 & -43.3 & 0.86 \\
2 & $2.33 \times F_{S W}$ & NCEP & n.a. & 91.5 & 113.1 & 0.53 \\
3 & $2.33 \times F_{S W}$ & Zillman (1972) (ID8) & n.a. & 57.7 & 95.1 & 0.35 \\
4 & Eq. (9) & SHIP & VISUAL & -0.01 & 29.9 & 0.93 \\
5 & Eq. (9) & NCEP & NCEP & 103.9 & 121.1 & 0.58 \\
6 & Eq. (9) & Zillman (1972) (ID8) & CLIM & 66.8 & 100.6 & 0.38 \\
\hline
\end{tabular}


addition, due to the important imprint of cloud fraction on errors, the linear equation leads to slightly lower bias than the more complex regression. However, all this has a cost: using monthly climatologies induces the loss of daily variations, as indicated by the poor values of the correlation coefficient.

\subsection{Longwave radiation}

Computation methods: Many equations for the downwelling longwave radiation flux are found in the literature. A large number of them were reviewed by Key et al. (1996). Based on their conclusions, we use the Efimova (1961) parameterization of the clear-sky flux used in the Jacobs (1978) parameterization for all skies:

$F_{L W}=\varepsilon \sigma T^{4}(0.746+0.0066 e)(1+0.26 c)$,

where $\varepsilon=0.97$ is the surface emissivity, $\sigma$ is the constant of StefanBoltzmann, $T$ is the air temperature (in Kelvins), $e$ is the water vapour pressure (in $\mathrm{hPa}$ ), and $c$ is the cloud fraction (0-1). The other formulation we use is from Goosse (1997), who introduced a parameterization based on Berliand and Berliand (1952):

$F_{L W}=\varepsilon \sigma T^{4}[1-f(c)(0.39-0.05 \sqrt{e / 100})]$,

where $f(c)=1-\alpha c^{2}$, with $\alpha$ between 0 and 1, being a function of latitude and describing the cloud effect on incoming longwave radiation.

Results: We compare several time series of $F_{L W}$ to observations (Fig. 6 and Table 5). Methods of computation include the direct use of NCEP reanalyses as well as the parameterizations of Berliand and Berliand (1952) and Efimova (1961) forced with cloud fraction, humidity and temperatures from (i) in situ data, (ii) NCEP reanalyses and (iii) a hybrid combination of NCEP temperatures and climatologies of cloud fraction (Berliand and Strokina, 1980) and relative humidity (Trenberth et al., 1989).

NCEP LW radiation flux time series have a lower bias, and of opposite sign, than earlier found for SW radiation ( -20 and $-45 \mathrm{~W} / \mathrm{m}^{2}$ ). Using in situ atmospheric data, Efimova's (1961) equation has the lowest bias ( 14.3 and $0.4 \mathrm{~W} / \mathrm{m}^{2}$ ) among all time series. The problematic points seem to be associated to low $F_{L W}$ values (Fig. 6), corresponding to clear skies, as already pointed by Key et al. (1996) in the Arctic. Time series from Berliand and Berliand (1952) and in situ data have biases of -19.7 and
$-35.0 \mathrm{~W} / \mathrm{m}^{2}$, only slightly better than NCEP. The latter parameterization underestimates even the clear sky incoming LW flux.

By combining parameterizations with atmospheric data from NCEP reanalyses, the bias compared to NCEP $F_{S W}$ time series increases. This is particularly true for Berliand and Berliand's (1952) equation $\left(-41\right.$ and $\left.-83 \mathrm{~W} / \mathrm{m}^{2}\right)$. In contrast, combining climatologies with equations, drastically reduce the biases, in particular if Efimova's (1961) parameterization is used, with biases of 0.75 and $-3.8 \mathrm{~W} / \mathrm{m}^{2}$, but reduces the correlation with observed time series.

\section{Discussion and conclusions}

In this paper, we used in situ atmospheric and radiation observations from two drifting stations over Antarctic sea ice, one late winter/early spring station (SIMBA) and one late springearly summer station (ISPOL). Observations were compared to NCEP reanalyses and forcing formulations used in large-scale sea ice models.

NCEP-NCAR reanalyses were found to be in good agreement with observations of the assimilated variables (temperature, winds, humidity), with larger uncertainties for the variables that are not assimilated (humidity, clouds, and radiation) (Parrish and Derber, 1992). The late spring-early summer air temperature observed at ISPOL was relatively close to the snow melting point and reconstructed with an almost zero bias by NCEP. At SIMBA, the air temperature was colder than at ISPOL and reconstructed by NCEP with a $1.2{ }^{\circ} \mathrm{C}$ cold bias. In addition to the winter bias, reanalyzed temperatures show significant errors on a daily basis at both SIMBA and ISPOL stations, with RMS errors from 1.4 to $3.8{ }^{\circ} \mathrm{C}$. Our results are consistent with Vihma et al. (2002), who compared NCEP reanalysis to a one-year time series of meteorological data from buoys over sea ice in the Weddell Sea in 1996. They found an average cold bias of $3.2{ }^{\circ} \mathrm{C}$ in NCEP temperatures with larger values in winter and smaller values in summer. Our analysis supports this tendency of NCEP to significantly underestimate air temperature during cold events. Finally, the NCEP temperature biases found over pack sea ice at SIMBA, ISPOL (this study) and in the Weddell Sea (Vihma et al., 2002) contrast with large biases $\left(-5\right.$ to $-10{ }^{\circ} \mathrm{C}$ ) obtained by comparing NCEP reanalyses to coastal meteorological station data (Bromwich and Fogt, 2004), supporting the hypothesis that the coastal cold bias in NCEP

Table 5

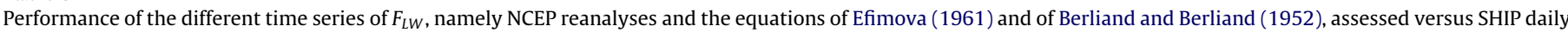

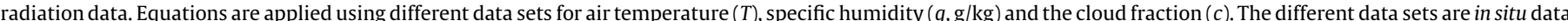

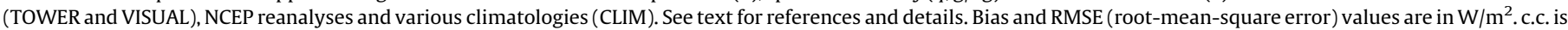
the correlation coefficient.

\begin{tabular}{|c|c|c|c|c|c|c|c|}
\hline ID & Comput. meth. & $T$ & $q$ & $c$ & Bias & RMSE & c.c. \\
\hline \multicolumn{8}{|c|}{ SIMBA } \\
\hline 1 & NCEP & n.a. & n.a. & n.a. & -20.3 & 25.8 & 0.86 \\
\hline 2 & Berliand and Berliand (1952) & TOWER & TOWER & VISUAL & -19.7 & 25.4 & 0.88 \\
\hline 3 & Berliand and Berliand (1952) & NCEP & NCEP & NCEP & -40.9 & 43.9 & 0.78 \\
\hline 4 & Berliand and Berliand (1952) & NCEP & CLIM & CLIM & -54.2 & 54.3 & 0.82 \\
\hline 2 & Efimova (1961) & TOWER & TOWER & VISUAL & 14.3 & 15.6 & 0.97 \\
\hline 3 & Efimova (1961) & NCEP & NCEP & NCEP & -1.5 & 17.8 & 0.84 \\
\hline 4 & Efimova (1961) & NCEP & CLIM & CLIM & 0.75 & 18.2 & 0.82 \\
\hline \multicolumn{8}{|c|}{ ISPOL } \\
\hline 1 & NCEP & n.a. & n.a. & n.a. & -44.8 & 44.7 & 0.59 \\
\hline 2 & Berliand and Berliand (1952) & TOWER & TOWER & VISUAL & -35.0 & 40.2 & 0.85 \\
\hline 3 & Berliand and Berliand (1952) & NCEP & NCEP & NCEP & -83.4 & 83.4 & 0.49 \\
\hline 4 & Berliand and Berliand (1952) & NCEP & CLIM & CLIM & -68.7 & 68.7 & 0.43 \\
\hline 2 & Efimova (1961) & TOWER & TOWER & VISUAL & 0.4 & 6.2 & 0.93 \\
\hline 3 & Efimova (1961) & NCEP & NCEP & NCEP & -22.0 & 23.2 & 0.48 \\
\hline 4 & Efimova (1961) & NCEP & CLIM & CLIM & -3.8 & 14.1 & 0.43 \\
\hline
\end{tabular}


near-surface temperature near Antarctica is due to unresolved station altitude and neighborhood topography.

For winds averaged over long time steps, no bias was found but the analysis was complicated due to the various heights of instruments. Despite these complications, NCEP winds agree remarkably well with observations. In particular, at SIMBA, NCEP $10 \mathrm{~m}$ wind speeds were almost always between TOWER and SHIP values. We found a systematic overestimation of specific humidity by NCEP, by 0.2 and $0.6 \mathrm{~g} / \mathrm{kg}$ at SIMBA and ISPOL, respectively. When specific humidity and air temperature are used to compute relative humidity, the errors in those two variables add up, leading to relative humidities always well above $100 \%$, precluding the use of NCEP reanalysis data for relative humidity purposes over sea ice. Relative humidity was always near-saturation with respect to ice at SIMBA, but not at ISPOL, in contrast to earlier studies (Andreas et al., 2002).

Cloud fraction is underestimated in NCEP reanalyses compared to visual estimates at SIMBA and to a cloud fraction proxy at ISPOL. Our finding confirms an earlier suggestion from a comparison of the NCEP radiation budget to ISCCP data (Betts et al., 2006). Consistently, the incoming SW fluxes are largely overestimated by NCEP, by 42 and $109 \mathrm{~W} / \mathrm{m}^{2}$, while the incoming LW fluxes are slightly underestimated by NCEP, by 20 and $45 \mathrm{~W} / \mathrm{m}^{2}$ at SIMBA and ISPOL, respectively. Those deficiencies in cloud and radiation are quite comparable with those found at Point Barrow on the Northern Alaskan Coast (Walsh et al., 2009).

The use of NCEP temperatures and winds seems acceptable at climate time scales for the large-scale simulation of Antarctic sea ice evolution. However, this is not the case for radiation fluxes. Hence, it is preferable to parameterize the latter. Lower biases are obtained by using empirical equations forced by monthly climatologies of cloud fraction and relative humidity. However, this has a cost: using monthly climatologies leads to loss of daily variations, as indicated by the poor values of the correlation coefficient.

The largest errors were found in the solar radiation flux. In the Arctic, Lindsay (1998) used large amounts of data and could precisely tune cloud optical depth seasonally and hence suggested the use of Shine's (1984) parameterization to compute the shortwave radiation flux. In the Antarctic, there are not enough data to apply the same procedure. Hence, at this stage, using Zillman's (1972) equation forced by monthly climatologies of cloud fraction and relative humidities is the best choice to compute the shortwave radiation flux. However, this leads to an overestimation of the shortwave flux by $20-30 \mathrm{~W} / \mathrm{m}^{2}$. As far as longwave radiation flux is concerned, the combination of the equation of Efimova (1961) with NCEP temperatures and monthly climatologies of cloud fraction and relative humidity gives remarkably low biases, on the order of $1 \mathrm{~W} / \mathrm{m}^{2}$. One needs to keep in mind that using monthly climatologies of cloud cover highly deteriorates the day-to-day and interannual variability in the radiation fluxes. Similarly, photosynthetically available radiation has the lowest biases compared to observations when parameterized using Zillman's (1972) equation and climatologies.

The results of the present study constitutes a first assessment of sea ice model radiation forcings in the Southern Ocean. However, some issues limiting the applicability of our conclusions must be kept in mind. First, only two relatively short data sets over particular locations and seasons were used. Hence, our results do not apply either for winter or for the entire sea ice covered Southern Ocean. In addition, using only two months of data precludes any assessment of interannual variability. Larger data sets are clearly required to overcome those issues. Finally, it was assumed that point measurements are representative of the whole model grid cell. This likely is a reasonable approximation for daily averages of most variables. However, the presence of mesoscale features such as polynyas or the proximity of the ice edge could influence the comparison.
It is difficult, if not impossible to evaluate reanalysis products over sea ice using independent data sets. Sea ice observations are almost always conducted near a research ship collecting meteorological data, which are in turn assimilated by reanalysis systems. This is the case for both data sets used here, as meteorological data from $R / V$ N.B. Palmer and $R / V$ Polarstern are included in the COADS data set, which is assimilated by the NCEP reanalysis system (Parrish and Derber, 1992; Kalnay et al., 1996). The analysis presented here shows that present hindcast simulations of sea ice in the Southern Ocean (e.g., Vancoppenolle et al., 2009; Timmermann et al., 2009) suffer from errors in the forcing. Those errors may be larger in data-poor regions. Given the importance of cloud fraction for the radiation fluxes, it seems desirable to improve cloud forcing data, e.g., use recent cloud cover products (e.g., Hatzianastassiou et al., 2001). Once the errors in the forcing are reduced, further improvements to models can be achieved in order to improve future climate projections. This study focussed on forcing errors should not hide the great value of atmospheric reanalyses for large-scale ice-ocean modelling.

\section{Acknowledgments}

This study was initiated on $R / V$ N.B. Palmer, hence members of the SIBCLIM, Palmer's Captain Mike and crew as well as SIMBA cruise fellows are warmly thanked for inspiration. Bruno Delille, Klaus Meiners, Christian Fristen, Ivan Grozny and Christiane Lancelot are acknowledged for discussions, Mike Lewis for the ice thickness and surface temperature data at SIMBA, Wesley Ebisuzaki and Anna Borovikov for help on the NCEP/NCAR assimilation system. The NCEP/NCAR reanalysis data were provided by the National Oceanic and Atmospheric Administration-Cooperative Institute for Research in Environmental Sciences Climate Diagnostics Center, Boulder, online at http://www.cdc.noaa.gov. ISPOL data were kindly made available by AWI. Authors gratefully acknowledge support from the projects BELCANTO (Belgian Science Federal Policy Office), SIBCLIM (Communauté Française de Belgique, ARC 02/07-287), and Sea-ice biogeochemistry in polar oceans (FRFC-FNRS). M.V. and H.G. are supported by FNRS. P.H. and J.L. were supported by the Australian Government's Cooperative Research Centre's Program through the Antarctic Climate and Ecosystems Cooperative Research Centre. K.L. and S.A. were supported by United States NSF Office of Polar Programs Grants ANT-06-32282 and ANT-07-03682. Finally, sincere thanks to the two anonymous Referees and Editor Cathy Geiger whose careful reading significantly improved this manuscript.

\section{Appendix A. Radiation heat fluxes and total quanta}

Measurements of downwelling radiative energy fluxes $\left(\mathrm{W} / \mathrm{m}^{2}\right)$ in the longwave $\left(F_{L W}, 4-50 \mu \mathrm{m}\right)$ and shortwave $\left(F_{S W}, 0.3-3 \mu \mathrm{m}\right)$ wavelength bands were performed. In addition, the total number of incoming quanta $Q_{P A R}$ (quanta $/ \mathrm{m}^{2} / \mathrm{s}$ ) in the visible region $(0.4-$ $0.7 \mu \mathrm{m}$ ) - referred to as photosynthetically active radiation (PAR) was measured. Both $F$ and $Q$ in a given wavelength interval $\left[\lambda_{1}, \lambda_{2}\right]$ can be formulated using the spectral irradiance $\partial E / \partial \lambda\left(\mathrm{W} \mathrm{m}^{-2} \mathrm{~m}^{-1}\right)$, i.e., the incoming energy over all incident angles within a given wave band:

$$
\begin{aligned}
& Q\left(\lambda_{1}, \lambda_{2}\right)=\int_{\lambda_{1}}^{\lambda_{2}} \frac{\partial E}{\partial \lambda} \frac{\lambda}{h c} d \lambda, \\
& F\left(\lambda_{1}, \lambda_{2}\right)=\int_{\lambda_{1}}^{\lambda_{2}} \frac{\partial E}{\partial \lambda} d \lambda .
\end{aligned}
$$


While $F_{S W}$ and $F_{L W}$ are necessary to assess the surface energy budget in physical models, $Q_{P A R}$ is required to compute the primary production rate in biochemical models. $Q_{P A R}$ is frequently expressed in $\mu \mathrm{E} / \mathrm{m}^{2} / \mathrm{s}$. $1 \mathrm{E}=1$ Einstein $=1$ mole of quanta.

\section{Appendix B. Cloud fraction proxy}

The sky state has a strong impact on radiative fluxes. Therefore, cloud fraction information can be derived from the radiative fluxes. We defined the cloudiness binary index $C_{i r}$ using hourly anomalies (i.e., the difference between actual hourly values and the value at the corresponding hour from the mean diurnal cycle) of radiative fluxes. $C_{i r}$ equals 1 if the hourly anomalies of $F_{L W}$ and $F_{S W}$ are, respectively, positive and negative and 0 if one of these two conditions is not verified. During the night, only the LW anomalies are used. From the VISUAL cloud fraction data set, the visual cloudiness binary index $C_{i v}$ is defined to be 1 if observed cloud fraction (in tenths) $>3 / 10$ and 0 otherwise. As expected, $C_{i r}$ and $C_{i v}$ have the same value $87 \%$ of the time. Finally, we defined the daily cloud fraction proxy $C_{r}$ (in tenths) as the daily average $C_{i r}$ multiplied by 10 . Visual cloud fraction $C_{v}$ and reconstructed cloud fraction $C_{r}$ have a correlation coefficient of 0.78 . $C_{r}$ is on average slightly ( 0.66 tenths) lower than $C_{r}$. Therefore, it is considered that cloud fraction can be reasonably well reconstructed from hourly recordings of SW and LW radiation.

\section{References}

Andreas, E., Guest, P., Persson, P., Fairall, C.W., Horst, T., Moritz, R., Semmer, S., 2002. Near-surface water vapor over polar sea ice is always near ice saturation. Journal of Geophysical Research 107, 8032. doi:10.1029/2000JC000411.

Andreas, E., Perssonn, P., Jordan, R., Horst, T., Guest, P., Grachev, A., Fairall, C., 2010. Parameterizing turbulent exchange over sea ice in winter. Journal of Hydrometeorology, 11, 87-104, doi:10.1175/2009JHM1102.1.

Andreas, E.L., Jordan, R.E., Makshtas, A.P., 2004. Simulations of snow, ice and nearsurface atmospheric processes on Ice Station Weddell. Journal of Hydrometeorology 5, 611-624.

Arzel, O., Fichefet, T., Goosse, H., 2006. Sea ice evolution over the 20th and 21st centuries as simulated by current AOGCMs. Ocean Modelling 12, 401-415. doi:10.1016/j.ocemod.2005.08.002.

Aumont, O., Maier-Reimer, E., Blain, S., Monfray, P., 2003. An ecosystem model of the global ocean including Fe, Si, P colimitations. Global Biogeochemical Cycles 17 (2), 1060. doi:10.1029/2001GB001745

Berliand, M., Strokina, T.G., 1980. Global distribution of the total amount of clouds (in Russian). Hydrometeorological, Leningrad, p. 71.

Berliand, M.E., Berliand, T.G., 1952. Determining the net long-wave radiation of the earth with consideration of the effect of cloudiness (in Russian). Izvestiya Akademii Nauk SSSR, Seriya Geofizicheskaya 1.

Betts, A., Zhao, M., Dirmeyer, P.A., Beljaars, A.C.M., 2006. Comparison of ERA40 and NCEP/DOE near-surface data sets with other ISLSCP-II data sets. Journal of Geophysical Research 111, D22S04. doi:10.1029/2006JD007174.

Bitz, C., Gent, P., Woodgate, R., Holland, M., 2006. The influence of sea ice on ocean heat uptake in response to increasing $\mathrm{CO}_{2}$. Journal of Climate 19 , 2437-2450.

Blackadar, A.K., 1962. The vertical distribution of wind and turbulent exchange in a neutral atmosphere. Journal of Geophysical Research 67 (8), 3095-3102.

Brandt, R.E., Warren, S.G., Worby, A.P., Grenfell, T.C., 2005. Surface albedo of the Antarctic sea ice zone. Journal of Climate 18, 3606-3622.

Bromwich, D.H., Fogt, R.L., 2004. Strong trends in the skill of the ERA-40 and NCEPNCAR in the high and midlatitudes of the Southern Hemisphere, 1958-2001. Journal of Climate 17, 4603-4619.

Bromwich, D.H., Fogt, R.L., Hodges, K.I., Walsh, J.E., 2007. A tropospheric assessment of the ERA-40, NCEP and JRA-25 global reanalyses in the polar regions. Journal of Geophysical Research 112, D10111. doi:10.1029/2006JD007859.

Cavalieri, D.J., Parkinson, C.L., 2008. Antarctic sea ice variability and trends, 1979-2006. Journal of Geophysical Research 113, C07004. doi:10.1029/ 2007JC004564, 10.1029/2007JC004564.

Chou, S.-H., Curran, R., 1981. The effects of surface evaporation parameterizations on climate sensitivity to solar constant variations. Journal of Atmospheric Sciences 38, 931-938.

Comiso, J., Parkinson, C.L., Gersten, R., Stock, L., 2008. Accelerated decline in the Arctic Sea Ice cover. Geophysical Research Letters 35, L01703. doi:10.1029/2007 GL031972.

Déry, S.J., Tremblay, L.-B., 2004. Modeling the effects of wind redistribution on the snow mass budget of polar sea ice. Journal of Physical Oceanography 34, 258-271.
Efimova, N.A., 1961. On methods of calculating monthly values of net long-wave radiation. Meteorologiya i Gidrologiya 10, 28-33.

Fichefet, T., Goosse, H., Morales Maqueda, M.A., 2003. A hindcast simulation of Arctic and Antarctic sea ice variability, 1955-2001. Polar Research 22, 91-98.

Frouin, R., Pinker, R.T., 1995. Estimating photosynthetically active radiation (PAR) at the Earth's surface from satellite observations. Remote Sensing of Environment 51, 98-107.

Goosse, H., 1997. Modeling the large-scale behavior of the coupled ocean-sea ice system. Ph.D. Thesis, Université Catholique de Louvain, Louvain-la-Neuve, Belgium.

Goosse, H., Fichefet, T., 1999. Importance of ice-ocean interactions for the global ocean circulation: a model study. Journal of Geophysical Research 104 23,337-23,355

Haas, C., Nicolaus, M., Willmes, S., Worby, A.P., Flinspach, D., 2008. Sea ice and snow thickness and physical properties of an ice floe in the western Weddell Sea and their changes during spring warming. Deep-Sea Research II 55 963-974. doi:10.1016/j.dsr2.2007.12.020.

Hatzianastassiou, N., Cleridou, N., Vardavas, I., 2001. Polar cloud climatologies from ISCCP C2 and D2 datasets. Journal of Climate 14, 3851-3862.

Heil, P., Allison, I., 1999. The pattern and variability of Antarctic sea-ice drift in the Indian Ocean and Western Pacifics. Journal of Geophysical Research 104 (C7), $15,789-15,802$

Heil, P., Hutchings, J., Worby, A., Johansson, M., Launiainen, J., Haas, C., W.D. Hibler 2008. Tidal forcing on sea-ice drift and deformation in the Western Weddell Sea during December 2004. Deep-Sea Research II 55 (8-9), 943-962.

Hellmer, H.H., Schröder, M., Haas, C., Dieckmann, G.S., Spindler, M., 2008. The ISPOL drift experiment. Deep-Sea Research II 55, 913-917. doi:10.1016/ j.dsr2.2008.01.001.

Holland, M., Raphael, M., 2006. Twentieth century simulation of the southern hemisphere climate in coupled models. Part II: sea ice conditions and variability. Climate Dynamics 26, 229-245. doi:10.1007/s00382-005-0087-3.

Jacobs, J., 1978. Energy budget studies in relation to fast-ice breakup processes in Davis Strait. In: Radiation Climate of Broughton Island (Chapter), pp. 105-120, INSTAAR, University of Colorado.

Kalnay, E., Kanamitsu, M., Kistler, R., Collins, W., Deaven, D., Gandin, L., Iredell, M., Saha, S., White, G., Woollen, J., Zhu, Y., Leetmaa, A., Reynolds, B., Chelliah, M., Ebisuzaki, W., Higgins, W., Janowiak, J., Mo, K., Ropelewski, C., Wang, J., Jenne, R., Joseph, D., 1996. The NCEP/NCAR 40-year reanalysis project. Bulletin of the American Meteorological Society 77, 437-471.

Key, J.R., Silcox, R.A., Stone, R.S., 1996. Evaluation of surface radiative flux parameterizations for use in sea ice models. Journal of Geophysical Research 101 (C2), 3839-3850.

Kistler, R., Kalnay, E., Collins, W., Saha, S., White, G., Woollen, J., Chelliah, M. Ebisuzaki, W., Kanamistu, M., 2001. The NCEP-NCAR 50-year reanalysis: monthly means CD-ROM and documentation. Bulletin of the American Meteorological Society 82 (2), 247-267.

LeQuéré, C., Rödenbeck, C., Buitenhuis, E.T., Conway, T., Langenfelds, R., Gomez, A., Labuschagne, C., Ramonet, M., Nakazawa, T., Metzl, N., Gillett, N., Heimann, M. 2007. Saturation of the Southern Ocean $\mathrm{CO}_{2}$ sink due to climate changes. Science 316 (5832), 1735-1738. doi:10.1126/science.1136188.

Lefebvre, W., Goosse, H., 2008. Analysis of the projected regional sea ice changes in the Southern Ocean during the 21st century. Climate Dynamics 30 59-76. doi:10.1007/s00382-007-0273-6.

Leonard, K.C., Cullather, R.I., 2008. Snowfall measurements in the Amundsen and Bellingshausen Seas, Antarctica. In: Proceedings of the Eastern Snow Conference, vol. 65, pp. 87-98.

Lewis, M.J., Tison, J.L., Weissling, B., Delille, B., Ackley, S.F., Brabant, F., Xie, H., 2011 Sea ice and snow cover characteristics during the winter-spring transition in the Bellingshausen Sea: an overview of SIMBA 2007. Deep-Sea Research II 58 (9-10), 1019-1038.

Lindsay, R.W., 1998. Temporal variability of the energy balance of thick Arctic pack ice. Journal of Climate 11, 313-331.

Madec, G., 2008. NEMO reference manual, ocean dynamics component: NEMO-OPA Preliminary version, Note du Pole de modélisation No. 27, ISSN No. 1288-1619, Institut Pierre-Simon Laplace (IPSL), France.

Mathiot, P., 2009, Influence du forçage atmosphérique sur la représentation de la glace de mer et des eaux de plateau en Antarctique dans une étude de modélisation numérique. Ph.D. Thesis, Laboratoire des Ecoulements Géophysiques et Industriels, Université Joseph Fourier, Grenoble, France.

Morel, A., Smith, R.C., 1974. Relation between total quanta and total energy for aquatic photosynthesis. Limnology and Oceanography 4, 591-600.

Nicolaus, M., Haas, C., Bareiss, J., Willmes, S., 2006. A model study of differences of snow thinning on Arctic and Antarctic first-year sea ice during spring and summer. Annals of Glaciology 44, 147-153.

Nicolaus, M., Haas, C., Willmes, S., 2009. Evolution of first-year and second-year snow properties on sea ice in the Weddell Sea during spring-summer transition. Journal of Geophysical Research 114, D17109. doi:10.1029/2008JD011227.

Nishi, Y., Tabeta, S., 2008. Relation of material exchange between sea ice and water to a coupled ice-ocean ecosystem at the Hokkaido coastal region of the Okhotsk sea-ice. Journal of Geophysical Research 113, C01003. doi:10.1029/2006JC004077.

Parkinson, C.L., Washington, W.M., 1979. A large-scale numerical model of sea ice. Journal of Geophysical Research 84, 311-337.

Parrish, D., Derber, J., 1992. The National Meteorological Center's Spectral Statistical-Interpolation Analysis System. Monthly Weather Review 120, 1747-1763. 
Pasquer, B., Laruelle, G., Becquevort, S., Schoemann, V., Goosse, H., Lancelot, C., 2005 Linking ocean biogeochemical cycles and ecosystem structure and function: results of the complex SWAMCO-4 model. Journal of Sea Research 53 (1-2), 93-108.

Peixoto, J.P., Oort, A.H., 1992. Physics of Climate. Springer-Verlag.

Pinto, J.O., Curry, J.A., McInnes, K.L., 1995. Atmospheric convective plumes emanating from leads 1 . Thermodynamic structure. Journal of Geophysical Research 100 (C3), 4621-4631.

Rothrock, D.A., Percival, D.B., Wensnahan, M., 2008. The decline in Arctic sea-ice thickness: separating the spatial, annual and interannual variability in a quarter century of submarine datasets. Journal of Geophysical Research 113, C05003. doi:10.1029/2007JC004252.

Shine, K., 1984. Parameterization of the shortwave flux over high albedo surfaces as a function of cloud thickness and surface albedo. Quarterly Journal of the Royal Meteorological Society 110, 747-764.

Stössel, A., Stössel, M.M., Kima, J., 2007. High-resolution sea ice in long term global ocean GCM integrations. Ocean Modelling 16 (3-4), 206-223. doi:10.1016/ j.ocemod.2006.10.001.

Stouffer, R.J., Russel, J., Spellman, M., 2006. Importance of ocean heat uptake in transient climate change. Geophysical Research Letters 33. doi:10.1029/ 2006 GL027242.

Tedesco, L., 2009. Modelling coupled physical-biogeochemical processes in icecovered oceans. Ph.D. Thesis, Università di Bologna.

Timmermann, R., Goosse, H., Madec, G., Fichefet, T., Ethé, C., Dulière, V., 2005. On the representation of high latitude processes in the orcalim global coupled sea iceocean model. Ocean Modelling 8, 175-201.

Timmermann, R., Danilov, S., Schröter, J., Bönig, C., Sidorenko, D., Rollenhagen, K. 2009. Ocean circulation and sea ice distribution in a finite element global sea-ice ocean model. Ocean Modelling 27 (3-4), 114-129. doi:10.1016/j.ocemod. 2008.10.009.

Tison, J.-L., Worby, A.P., Delille, B., Brabant, F., Papadimitriou, S., Thomas, D.N., de Jong, J., Lannuzel, D., Haas, C., 2008. Temporal evolution of decay summer first- year sea ice in the Western Weddell Sea, Antarctica. Deep Sea Research II 55, 975-987 . doi:10.1016/j.dsr2.2007.12.021.

Trenberth, K., Olson, J., Large, W., 1989. A global ocean wind stress climatology based on the ECMWF analyses. Technical Report NCAR/TN-338+STR, National Center for Atmospheric Research, Boulder, Colorado, 93pp.

Vancoppenolle, M., Fichefet, T., Goosse, H., Bouillon, S., Madec, G., Morales Maqueda, M.A., 2009. Simulating the mass balance and salinity of Arctic and Antarctic sea ice. 1. Model description and validation. Ocean Modelling 27 (1-2), 33-53. doi:10.1016/j.ocemod.2008.10.005.

Vancoppenolle, M., Goosse, H., de Montety, A., Fichefet, T., Tremblay, B., Tison, J.-L., 2010. Modeling brine and nutrient dynamics in Antarctic sea ice: the case of dissolved silica. Journal of Geophysical Research 115 (C2), C02005. doi:10.1029/ 2009JC005369.

Vihma, T., Uotila, J., Cheng, B., Launiainen, J., 2002. Surface heat budget over the Weddell Sea: buoy results and model comparisons. Journal of Geophysical Research 107 (C2), 3013. doi:10.1029/2000JC000372.

Vihma, T., Johansson, M., Launiainen, J., 2009. Radiative and turbulent surface heat fluxes over sea ice in the western Weddell Sea in early summer. Journal of Geophysical Research 114, C04019 . doi:10.1029/2008JC004995.

Walsh, J.E., Chapman, W.L., Portis, D.H., 2009. Arctic cloud fraction and radiative fluxes in atmospheric reanalyses. Journal of Climate 22, 2316-2334.

Worby, A.P., Geiger, C.A., Paget, M.J., Van Woert, S.F., Ackley, S.F., DeLiberty, T.L., 2008. Thickness distribution of Antarctic sea ice. Journal of Geophysical Research, 113, Co5S92. doi:10.1029/2007JC004254.

Zhang, J., 2007. Increasing Antarctic sea ice under warming atmospheric and oceanic conditions. Journal of Climate 20, 2515-2529. doi:10.1175/JCLI4136.1.

Zillman, J.W., 1972. A study of some aspects of the radiation and the heat budges of the southern hemisphere oceans. Bureau of Meteorology, Department of the Interior, Canberra, Australia, 562pp. 